San Jose State University

SJSU ScholarWorks

Master's Theses

Master's Theses and Graduate Research

1992

\title{
Perception similarities between caregiver and the cancer patient related to functional status
}

Marisa A. Silva

San Jose State University

Follow this and additional works at: https://scholarworks.sjsu.edu/etd_theses

\section{Recommended Citation}

Silva, Marisa A., "Perception similarities between caregiver and the cancer patient related to functional status" (1992). Master's Theses. 421.

DOI: https://doi.org/10.31979/etd.qp8v-fp5d

https://scholarworks.sjsu.edu/etd_theses/421

This Thesis is brought to you for free and open access by the Master's Theses and Graduate Research at SJSU ScholarWorks. It has been accepted for inclusion in Master's Theses by an authorized administrator of SJSU ScholarWorks. For more information, please contact scholarworks@sjsu.edu. 


\section{INFORMATION TO USERS}

This manuscript has been reproduced from the microfilm master. UMI films the text directly from the original or copy submitted. Thus, some thesis and dissertation copies are in typewriter face, while others may be from any type of computer printer.

The quality of this reproduction is dependent upon the quality of the copy submitted. Broken or indistinct print, colored or poor quality illustrations and photographs, print bleedthrough, substandard margins, and improper alignment can adversely affect reproduction.

In the unlikely event that the author did not send UMI a complete manuscript and there are missing pages, these will be noted. Also, if unauthorized copyright material had to be removed, a note will indicate the deletion.

Oversize materials (e.g., maps, drawings, charts) are reproduced by sectioning the original, beginning at the upper left-hand corner and continuing from left to right in equal sections with small overlaps. Each original is also photographed in one exposure and is included in reduced form at the back of the book.

Photographs included in the original manuscript have been reproduced xerographically in this copy. Higher quality 6" $\times 9$ " black and white photographic prints are available for any photographs or illustrations appearing in this copy for an additional charge. Contact UMI directly to order.

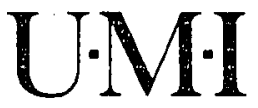

University Microfilms International

A Bell \& Howell Information Company

300 North Zeeb Road. Ann Arbor, Ml 48106-1346 USA

313:761-4700 800:521-0600 
Order Number 1350115

Perception similarities between caregiver and the cancer patient related to functional status

Silva, Marisa Alice, M.S.

San Jose State University, 1992 



\title{
PERCEPTION SIMILARITIES BETWEEN CAREGIVER
}

AND THE CANCER PATIENT RELATED TO FUNCTIONAL STATUS

\author{
A Thesis \\ Presented to \\ The Faculty of the Department of Nursing \\ San Jose State University
}

\author{
In Partial Fulfillment \\ of the Requirements for the Degree \\ Master of science
}

By

Marisa A. Silva

August 1992 
APPROVED FOR THE DEPARTMENT OF NURSING

Eimilie Mecer-i

Emilie Musci, D.N.SC., R.N.

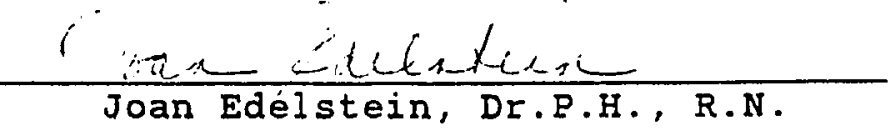

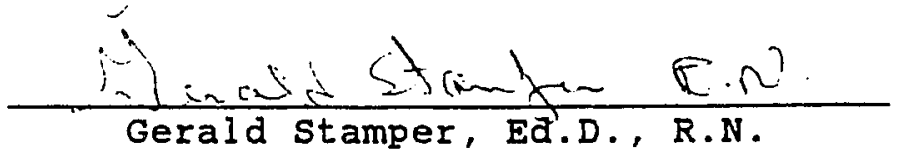

APPROVED FOR THE UNIVERSITY

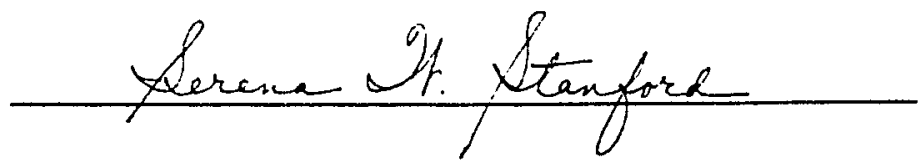




\section{ACKNOWLEDGEMENTS}

To Dr. Emilie Musci,

my parents, Frank and Laura Silva,

Dr. David Spira and Bethany Schroeder

for encouraging my continued perseverance

in completing this paper. To Dr. David Asquith

and Alan Miller who assisted me in interpreting

the statistics. To the many physicians and

nurses who supported and encouraged me

and who had faith in my ability

to complete the process. 


\section{ABSTRACT}

PERCEPTION SIMILARITIES BETWEEN CAREGIVER

AND THE CANCER PATIENT RELATED TO FUNCTIONAL STATUS

by Marisa Silva

This correlational study addresses perception similarities between caregivers and cancer patients related to functional status. Using a symbolic interactionism framework, a sample of 30 cancer patients and 30 caregivers was stuasied to determine congruency of perceptions. These dyads completed Bergner's Sickness Impact Profile (SIP) in an acute care setting. The SIP measures both physical and psychosocial aspects of sickness related dysfunction. This study demonstrated patients/caregivers shared similar overall perceptions. However, the findings illustrate that caregivers perceived cancer patients' functional status as more disabling than indicated in the patients' self report. Caregivers rated dysfunction higher in the following dimensions than did patients: psychosocial 100\%, physical 668, "personal habits" 608. Family perceptions are important in caregiving and should be recognized by health care workers as having an impact on patient outcomes. It is important that nurses be cognizant of the similarities and differences between caregiver and patient functional status perceptions in order to support effective communication and enhance effective coping when dealing with cancer. 
IIST OF TABLES . . . . . . . . . . . . . . . . . . . . viii Chapter

1. INTRODUCTION . . . . . . . . . . . . . . 1

Background . . . . . . . . . . . . . . 1

Problem . . . . . . . . . . . . . . . 4

Purpose of the study . . . . . . . . . . . . 9

Research Questions... . . . . . . . 10

Definition of Terms. . . . . . . . . . . . II

Summary. . . . . . . . . . . . • • • 12

2. CONCEPTUAL FRAMEWORK AND REVIEW OF

THE IITERATURE . . . . . . . . . . . . 14

Conceptual Framework . . . . . . . . . . . . 14

Review of the Literature . . . . . . . . . 16

Symbolic Interactionism . . . . . . . 17

Compliance Related to Perception . . . . 22

Family/Caregivers. . . . . . . . . 23

social support. . . . . . . . . . . . 24

summary. . . . . . . . . . . . . . 26

3. METHODOLOGY. . . . . . . . . . . . . . . 27

Design . . . . . . . . . . . . . . . . 27

subjects/setting . . . . . . . . . . . . 27

Human Subjects' Approval . . . . . . . . . 28

Data Collection. . . . . . . . . . . . . 30 
Instrument. . . . . . . . . . . . 30

Analysis Procedures. . . . . . . . . . 39

4. FINDINGS AND INTERPRETATION. . . . . . . . . 4 I

Demographic Characteristics of

the sample... . . . . . . . . . 41

Explanation of the Correlational

statistics. . . . . . . . . . 45

Physical Dimension Correlations. . . . . . 45

Psychosocial Dimension Correlations. . . . . 48

"Personal Habits" Correlations . . . . . . 50

Biographic Correlations. . . . . . . . . 55

other Significant Findings . . . . . . . . 58

Multiple Regression. . . . . . . . . . . 58

Total Patient SIP Score

Multiple Regression . . . . . . . . 59

Total Caregiver SIP Score

Multiple Regression . . . . . . . . 62

5. DISCUSSION . . . . . . . . . . . . . . 66

summary of the study. . . . . . . . . . 66

Comparison of Findings to Literature. . . . 66

Conclusions. . . . . . . . . . . . . . 67

Scope and Limitations. . . . . . . . . . 71

Recommendations. . . . . . . . . . . 72

Nursing Implications . . . . . . . . . 73 
Page

REFERENCES. . . . . . . . . . . . . . . . 74

APPENDICES

A. Sickness Impact Profile. . . . . . . 81

B. Consent from Institutional

Review Board. . . . . . . . . 98

c. Informed consent of subject. . . . . . 100

D. Cancer Patient Biographical

Data Form . . . . . . . . . 103

E. Primary Caregiver Biographical

Data Form . . . . . . . . 105

F. Cover Letter to Dr. Bergner. . . . . 107

G. Consent for Use of the

Sickness Impact Profile. . . . . 110

H. SIP Dimension and Total Scores . . . . 112 


\section{LIST OF TABLES}

Table Page

1. Sickness Impact Profile Dimensions. . . . . . 36

2. Demographic Characteristics of Cancer

Patients. . . . . . . . . .

3. Demographic Characteristics of

Caregivers. . . . . . . . . . . . 44

4. SIP Physical Dimension: Significant Patient/

Caregiver Category Correlations. . . . . 47

5. SIP Psychosocial Dimension: Significant

Patient/Caregiver Category

Correlations . . . . . . . . . . . . 49

6. SIP "Personal Habits" Dimension:

Significant Patient/Caregiver

Category Correlations. . . . . . . . 52

7. Total Patient SIP Score

Multiple Regression. . . . . . . . 60

8. Total Caregiver SIP Score

Multiple Regression. . . . . . . . 63

viii 
Chapter 1

INTRODUCTION

Background

The American Cancer Society (1991) predicts that 76 million Americans, or roughly $30 \%$ of the population, will be diagnosed with cancer during their lives. At present, over seven million people with a history of cancer are still living, and statistics reveal that just under half of this population has survived five years after receiving the original diagnosis (American Cancer Society, 1991). Thus, the five year survival rate for cancer patients has increased to 408 from $20 \%$ in the $1930 \mathrm{~s}$ and $33 \%$ in the $1960 \mathrm{~s}$. Furthermore, when adjusted for normal life expectancy, the five year survival rate reaches 50\%. Compilation of these statistics has led to the widespread recognition of cancer as a chronic illness.

Whereas cancer may lead to physical, personal, and social changes, medical and technological advances have enabled many cancer patients to anticipate a normal life expectancy despite the diagnosis. Many other cancer patients can anticipate that their lives will be prolonged through modern therapies. Yet cancer and its subsequent treatments can cause disturbing physical limitations, disfigurements, and temporary or permanent manifestations of both the disease and the remedies for it. For example, 
cancer patients may be limited in performing work or recreational activities. Since cancer patients need social support during these periods of physical limitations and stress, they may feel alienated when their social networks are reduced (Wortman, 1984, p. 2341).

Cobb (1976) defines social support as "information leading the subject to believe that he or she is cared for and loved, esteemed and a member of a network of mutual obligations" (p. 300). Along with others, Bloom (1982) has demonstrated that social support assists cancer patients to cope with illness. Large and close support networks are associated with more adaptive coping relationships (Berkman \& Syme, 1979; Lin, Ensel, Simeone \& Kuo, 1979). In addition to receiving social support, the cancer patient needs to give support to members of his or her social network (Lindsey, Norbeck, Carrieri \& Perry, 1981). The reciprocal nature of giving and receiving support assists the patient in maintaining an increased sense of perceived, legitimate support (Maxwell, 1982; 0'Connor, Wicker \& Germino, 1990).

According to the tenets of symbolic interactionism, a theory describing the effects of perception on subsequent behavior; social networks, support systems, the family and, most significantly, the primary caregiver, all have the ability to influence the cancer patient's understanding of his or her diagnosis (Kesselring, Dodd, Lindsey \& strauss, 
1986). Perceptions are important components of coping (Given \& Given, 1984). On the one hand, the negative perception of cancer as an ultimately terminal illness can affect not only the patient but also the social network, regardiess of the origin of the perception (Dirksen, 1989). Interpretation is the key to how perceptions are developed, incorporated, sustained, and altered over time. Social support systems help the patient to determine the perceived meaning of a cancer diagnosis (Lindsey, Ahmed \& Dodd, 1985).

The social support system has a role in influencing the cancer patient's ability to maintain a positive attitude and to cope with the tribulations of the moment. As part of this system, families, along with the patient, are inclined to draw upon previous coping strategies when dealing with a cancer diagnosis. Because families have usually dealt with various crises in the past, they tend to use similar and familiar tactics when confronting new dilemmas (Musci \& Dodd, 1990). If the family members have historically solved problems in a positive and effective manner, they will be creative and adaptive problem solvers; conversely, dysfunctional families with dysfunctional coping strategies either have difficulty in or are incapable of arriving at satisfying solutions to the same kinds of problems (Thorne, 1985). The families that are able to effectively confront the diagnosis and meaning of cancer can better meet the challenge of the care their loved one requires (MacVicar \& 
Archibold, 1976). These circumstances of interaction are important to consider regarding the dynamics of cancer, especially because approximately $75 \%$ of families will have at least one member diagnosed with the disease (American Cancer society, 1991).

In the matter of the day-to-day routines of life, for most people the social network is refined first to the family and then to the primary caregiver (Lindsey, Dodd \& Chen, 1985). The primary caregiver, defined as the individual who gives the most physical and emotional support to the cancer patient, is the person most able to help the patient to cope with the cancer diagnosis by encouraging him or her to mobilize resources and by giving meaning to the situation. The primary caregiver is likely to be a family member, often a spouse or a significant other. As the main support for the cancer patient, the primary caregiver should have a featured role in influencing the behavior of the patient. A detailed discussion of the complexities of the dynamics of circumstances and relationships follows.

\section{Problem}

The problem explored in this study was the perception differences and similarities between the cancer patient and the primary caregiver related to a cancer diagnosis. Perceptual alterations in the cancer patient and/or the primary caregiver may influence support and coping.

Even today, society views cancer as a death sentence, 
an attitude reflected in the feelings and convictions of individual cancer patients (Driever \& McCorkle, 1984). The patient may begin to accept the negative connotations associated with the disease when meaning and value are attributed to these perceptions and the subsequent expectations others have as a result of them. significant problems for the cancer patient that also pose demands on the practitioner and provide the researcher with categories of inquiry include the following: (a) general and specific changes as a result of the diagnosis of cancer, (b) challenges to coping, and (c) potentially altered perceptions and expectations of the cancer patient and his or her support system. Each problem is explored in the ensuing discussion.

When diagnosed, the cancer patient is usually aware of the potential physical, emotional, and social alterations that may occur as a result of the condition. For example, cancer can cause changes in weight and skin color, loss of hair, changes in bodily functions, nausea, vomiting, fatigue, weakness, and pain due to the disease and the attempts to treat it. While not all patients experience these symptoms, society equates such physical transformations with the normal response of an individual with cancer (Welch-McCaffrey, 1985). As a result of the disease and its anticipated consequences, the cancer patient often experiences changes in both body and self image 
(Stoner, 1985). The emotional impact the cancer patient feels can lead to fear regarding changes in lifestyle, life goals, self worth, and his or her existence (Mishel, Hostetter, King \& Graham, 1984). Along with physical and emotional alterations, the cancer patient often expects social changes such as isolation, role alterations, and loss of support systems (Tringali, 1986). In addition to personal concerns, the cancer patient also worries about the impact of his or her illness on family and support systems.

The cancer patient's family and support systems are affected by the cancer diagnosis as well, and they experience many of the same feelings; they are frequently fearful not only about their loved one's ordeal but also about the impact cancer my have on their own lives (Cassileth, Luske, Strouse, Miller, Brown \& Cross, 1985; Manchester-Berger, 1985). Such changes include role permutations, difficulties in interacting in normal ways with the cancer patient, and shifts in life plans.

The family often experiences alterations in roles when one of its members is diagnosed with cancer. The member may have been the breadwinner, caregiver, or family ruler prior to the diagnosis. The family may attempt to adjust to such changes by reversing, transposing, or transferring roles, acts potentially difficult for all involved (Lubkin, 1986). Family role changes may result in altered self-worth, financial hardship, anger, and frustration for members, 
adding to the already strained coping mechanisms of the family unit.

While family perceptions and interactions are important measures of coping, it is the primary caregiver who has the most influence on the cancer patient's ability to effectively cope with the diagnosis (Lindsey, Dodd \& Chen, 1985). The family and, most importantly, the primary caregiver are able to influence the cancer patient in both positive and negative ways through perceptions and actions. Because the cancer patient values the perceptions of the support system, he or she becomes capable of integrating these sentiments into his or her own belief system (Kesselring, Lindsey, Dodd \& Lovejoy, 1986).

Effective coping in the cancer patient is more likely to occur when congruent perceptions between the cancer patient and the primary caregiver exist regarding the impact of a cancer diagnosis (0'Connor et al., 1990). The meaning these two parties jointly give to the diagnosis affects their ability to cope with it. When the cancer patient and the primary caregiver view the situation as unfavorable, inflexible, and overwhelming, they feel as though they have little power (Dirksen, 1989). On the other hand, if both believe themselves capable of influencing the diagnosis, they maintain some degree of a sense of control. Consequently, when the cancer patient and the primary caregiver differ in their perceptions, coping becomes 
mutually difficult.

The cancer patient's potential for remaining able to perform activities of daily living (ADIS) is more likely to occur when he or she shares similar beliefs, perceptions, and expectations with the primary caregiver. Furthermore, if the primary caregiver is able to reinforce the cancer patient's belief in his or her ability to carry on with ADLs, the likelihood of the requisite behaviors occurring is high (McGough, 1990). The reverse holds true as well. In addition, differing perceptions between the cancer patient and the caregiver on this matter may create conflict. However, in such an instance the caregiver is in a position to help change the patient's beliefs, at which time the cancer patient will be inclined to look to the primary caregiver to validate his or her understanding and give meaning to the situation.

Finally, given recent changes in health care and technology, maintaining the ability to complete ADLs is an important component of coping on several levels. Today many cancer patients receive the bulk of their health care in the physician's office, as outpatients, and in the home. Hence, the primary caregiver is usually more directly involved than was once the case, thus elevating and making the supportive role more complex (Groenwald, 1987). Primary care has shitted from the hospital to the home and the burden falls on the family caregiver. 


\section{Purpose of the Study}

The purpose of this investigation was to evaluate perceptions between caregiver and the cancer patient related to functional status. The researcher studied and compared both the cancer patients' and the primary caregivers' perceptions of sickness related dysfunction in the cancer patient. Perceptual similarities and differences were of particular concern due to the potential consequences of incongruent feelings and beliefs.

The theory of symbolic interactionism describes the important role that perceptions play in subsequent actions. The logic of this theory is the basis for research that examines, evaluates, and describes the role that similar and differing perceptions fulfill, specifically in connection with a cancer diagnosis.

For the purposes of this study, perceptions of sickness related dysfunction or functional status were determined by analyzing results of the Sickness Impact Profile (SIP), which articulates both the physical and psychosocial dimensions of ADLs (See Appendix A). This tool was used to measure activities that the cancer patient performed in order to carry on his or her life. It is important to note that not only perceptions of physical dysfunction but also perceptions of psychological impairment and social alterations due to a cancer diagnosis were studied, since cancer affects the cancer patient, the family, significant 
others, and the primary caregiver in many ways.

It has been well documented that cancer patients should maintain as much independence in ADLs as possible. The researcher's investigation examined perceptions of cancer related outcomes that limit the ability to perform ordinary ADLs, as well as the similarities/differences of these perceptions between the cancer patient and the primary caregiver.

Although the research literature provides rich descriptions of the ways a cancer diagnosis affects the entire family unit, less research is available that discusses the specific relationship of the impact of cancer on the primary caregiver. Neither is substantial research available regarding the concerns of the primary caregiver and the difference/similarity of perceptions between the cancer patient and the primary caregiver. Therefore, this investigation is undertaken in an attempt to add information to this area of nursing research.

\section{Research Questions}

1. Do cancer patients and primary caregivers share similar perceptions of sickness related dysfunction in the cancer patient?

2. Do the variables of gender, age, educational level, relationship, and time since diagnosis correlate with perceptions of cancer related dysfunction?

3. Do a greater number of patients or caregivers 
perceive a higher degree of sickness related dysfunction in the cancer patient?

4. Which specific patient/caregiver perceptions exercise the greatest influence on the patients' and the caregivers' overall perceptions of dysfunction?

$$
\text { Definition of Terms }
$$

1. Activity of Daily Living (ADL) is a basic self-maintenance activity, such as bathing, eating, dressing, walking, that a person undertakes in order to carry on his or her life.

2. Cancer patient is any individual who is diagnosed with cancer and who is receiving any type of cancer-related care in an acute setting. This includes both inpatients and outpatients.

3. Family is a unit of interacting persons related by ties of marriage, birth, adoption, or other strong social bonds whose central purpose is to create, maintain, and promote the social, mental, physical and emotional development of each of its members (University of California, San Francisco, Department of Family Health Care Nursing, 198I).

4. Perception is awareness of the elements of environment through physical sensation or intuitive cognition. (Webster's Ninth New College Dictionary, 1983, p. 873).

5. Primary caregiver is the individual that the cancer 
patient identifies as the person who gives the greatest amount of emotional support, physical care, and general assistance in relation to the cancer diagnosis. More than one person can be a caregiver, but one primary caregiver has been identified in each circumstance for the purposes of this study.

6. Sickness related dysfunction is the alteration in maintaining ADLs due to illness which, for the purposes of this study, is cancer.

7. Social support as defined by Cobb (1976) is information leading the subject to believe that he or she is cared for and loved, esteemed and a member of a network of mutual obligations.

\section{Summary}

Due to technological advances and new forms of therapy, cancer is often considered a chronic illness. The individual with cancer can often anticipate a trajectory of physical and psychological changes as a result of the diagnosis. Cancer affects not only the cancer patient, but the primary caregiver as well. The primary caregiver often experiences psychosocial alterations and difficulty in coping. The cancer patient can be influenced by perceptions from the primary caregiver. These perceptions can be either positive or negative. Conversely, the primary caregiver can be influenced by the cancer patient's percepicioss. Fhase perceptual influences can impact support and coping. Due to 
the paramount role perceptions play in coping and support, this research is focused on the perceptions between caregiver and the cancer patient related to functional status. 
Chapter 2

CONCEPTUAL FRAMEWORK AND REVIEW OF THE LITERATURE

Conceptual Framework

This study focused on perceptions in an attempt to gain a better understanding of the relationship between cancer patients' and primary caregivers' response to a cancer diagnosis as a result of external stimuli. Because human responses to circumstances concern nurses in general and hence the practice and delivery of nursing care, this researcher focused on the formation of perceptions in response to human, social, and environmental interactions in her preliminary research. Due to its applicability to the questions posed, this researcher chose symbolic interactionism as a foundation and conceptual framework on which to base the study described here.

The scholars who have contributed to the development of symbolic interactionism emanate from varied disciplines. The most influential contributors include Blumer and Mead, who above all others have laid the foundation for studying the ways in which individuals are in constant interaction with their surroundings. According to Blumer (1969, p. 2), the following three premises are the basis of the theory:

1. human beings act toward stimuli on the basis of the meaning that the stimuli have for them, 2. the meaning of such stimuli is derived from, or 
arises out of, the social interaction that one has with one's feliows, and

3. these meanings are handed in, and modified through, an interpretive process used by the person in dealing with the things he encounters. To elaborate on the concept of symbolic interactionism first described in chapter 1 of this research, the cancer patient interprets the diagnosis based on the meaning cancer has for him or her. The cancer patient's personal meaning is the result of interactions with social systems significant to him or her. The meaning of this perception can be influenced through an interpretive process while the cancer patient interacts with his or her social system and set of significant others.

In most instances, the primary caregiver has the greatest influence on the patient's perception of the cancer diagnosis, as well as the greatest ability to change his or her perceptions. Conversely, the cancer patient can influence the primary caregiver's interpretation of the meaning of the disease. The range of interactions and their results create an ongoing, reflexive process.

When studying cancer patients and primary caregivers, it is important to acknowledge the role of social interaction on health outcomes. These parties continue to have social connections, which are symbolic in nature and can influence behavior. As an example, Kesselring, Dodd, 
Lindsey, and strauss (1986) used symbolic interactionism as a conceptual framework for their study of attitudes regarding cancer and its treatment among swiss patients. The researchers believed that the meaning ascribed to a cancer diagnosis could be influenced by the perception of others and by the patient's social surroundings. During the research, subjects were given an attitude questionnaire of several open-ended questions. Their findings led the researchers to conclude that only the cancer patient and his or her significant other could describe the perception that the cancer diagnosis held for them both. Kesselring, Dodd, Lindsey and strauss then stressed that in order to positively influence coping, nurses and other health care professionals had to be aware of perceptions from the patient's and the significant other's point of view. They further asserted that it is not the disease as much as it is the perception of the situation arising from the disease that influences coping.

Review of the Literature

The investigator's review of the related literature yielded many articles describing components of this research. Because this research is a pilot study, no articles were found specifically describing the present work. For ease of interpretation, this review is divided into the following four categories: (a) symbolic interactionism/perceived meaning, (b) compliance related to 
perception, (c) family/caregivers, and (d) social support. While several articles may fit into more than one category, the articles are described only in the area the researcher deemed to be most appropriate.

\section{Symbolic Interactionism}

Several articles describe the phenomena of symbolic interactionism and perceived meaning. Although the terminology of the latter is not always incorporated, the concept is nonetheless well demonstrated.

The first relevant article, "Attitudes of Patients Living in Switzerland About Cancer and its Treatment," by Kesselring, Dodd, Iindsey and Strauss (1986) was previously described in the conceptual framework of this study. The article demonstrates the importance of the concept of symbolic interactionism. Kesselring, Lindsey, Dodd, and Lovejoy (1986) studied the social networks and the social support perceived by swiss cancer patients. In their work, the Norbeck Social Support Questionnaire (NSSQ) was administered to 42 Swiss-German cancer patients as a means of determining perceptions of social support. The researchers conciuded that perceived social support had a positive influence on coping with a cancer diagnosis. Lindsey, Ahmed, and Dodd (1985) studied the effect of social support on Egyptian cancer patients and their subsequent outcomes. A sample of 40 Egyptian cancer patients were given the NSSQ, after which it was determined that cancer 
patients place much value on support groups, particularly family. Perceptions of social support were also found to be an important component of coping with a cancer diagnosis. Lindsey, Dodd and Chen (1985) studied the social support network of Taiwanese cancer patients. A sample of 670 respondents comprised one of the populations studied, a sample that included seven cultural groups in California. Each group demonstrated that individuals with perceived strong social support were found to have more positive health outcomes. Those cancer patients with high social support were discovered to be four times as likely to be in otherwise excellent health. A sample of 40 Taiwanese cancer patients being treated in Taiwan was studied and compared to the 670 California cancer patients. The NSSQ was used to establish the perception of social support in the Taiwanese cancer patients. Consistent with other cultural groups, the family was considered the main social support system. significantly, social support was shown to have a direct correlation with improved health regardless of cultural background. The researchers also established perceived social support to be a strong indicator of positive health outcomes. While some minor differences between cultures exist, these replication studies reveal that perceived support plays an integral role in health outcomes and coping.

Both a conceptual framework and a nursing model were 
developed that relate to the concept of perceived meaning and symbolic interactionism. Dirksen (1989) developed the former specific to perceived well-being in melanoma survivors. After a review of the literature, she found that locus of control, social support, and self-esteem all had an impact on perceived well being. She based her conceptual framework on these findings and acknowledged that the perception of social support influences the perception of well-being in the melanoma patient. Given and Given (1984) developed a nursing model describing factors that contribute to the likelihood of a cancer patient complying with a treatment regime. Their model also stresses the importance of perceptions, which are attributed with more value than the actual event in terms of compliance. Personal perceptions as well as the perceptions of significant others impact positive behaviors.

Musci and Dodd (1990) studied self-care behaviors of cancer patients, along with the affective states of family members as well as the level of family function. The authors acknowledge that family perceptions have an impact on the cancer patient's perception of illness and therefore on coping. This longitudinal study covered a three to four month period during which patients and families were evaluated with the use of various instruments, including the Profile of Mood States, the Family Crisis Oriented Personal Scales, and Self-Care Behavior Logs. Describing cancer as a 
family experience, Musci and Dodd found that patients and family members use similar coping strategies. Although the patient was found to be the primary self-care agent, while the family was involved in care to a lesser degree, the researchers distinguished the role of perceptions in coping. Bloom (1982) studied social support, accommodation to stress, and adjustment to breast cancer and found that social support was an important component of the coping process in cancer patients. The author describes the development of self-concept during childhood, when the individual identifies himself or herself as a being. This development occurs subsequent to the child's perception of the meaning of interactions with others, as well as the child's perception of how others react to him or her. Self-concept changes through life and is influenced by new circumstances and relationships, in addition to the ways in which the individual perceives these situations. For example, if an ill patient has a healthy self-concept and a strong social support system, then his or her coping will be positively influenced. Social support is the strongest indicator of a healthy coping response and has indirect effects on all three measures of adjustment, including self-concept, sense of power, and psychological distress. Three further studies demonstrate the important role perceptions play in subsequent health outcomes. A study of perceived self-efficacy among arthritis patients conducted 
by Lorig, Chastain, Ung, Shoor, and Holman in 1989, compared arthritis patients in a control group without intervention to arthritis patients in an experimental group whose treatment was participation in a self management course. In a replication study subsequent to the original work, the researchers found that it was the perception of control or self-efficacy rather than the intervention that resulted in positive health outcomes.

Andolsek and Clapp-Channing (1988) studied patients in an active family practice and found that 20 percent were caregivers. Of interest is their conclusion that the caregivers who perceived the role as difficult and uncontrollable presented to the practice with clinical disturbances more frequently than the caregivers who perceived the role as controllable. The researchers provided their study group with a checklist for monitoring health indicators, but found perceptions to be a stronger indicator of health outcomes than was use of the checklist. Mishel et al. (1984) studied the influence of uncertainty, optimism, seriousness of the illness, and control over physical function on psychological adjustment in 54 women with gynecological cancer. The researchers found that patients with more uncertainty and less optimism experienced more problems with social interactions. According to the authors, the purpose of social systems is to give meaning to events in order to reduce uncertainty. 
Mishel et al. found that support and perception of control were strong indicators of positive health outcomes.

All three articles demonstrate the power of perceptions in relation to health outcomes. Furthermore, although the researchers did not expect the findings, their work revealed perception to be the most influential factor in determining positive coping.

\section{Compliance Related to Perception}

Compliance has been shown to be related to perception, specifically perceptions of social support. For example, McGough (1990) described the social support of people with AIDS. Her article stresses the importance of assessing and encouraging social support. In this descriptive article, the researcher found that social support assists with coping and self-esteem and has a strong influence on both the psychological and physiological well-being of the patient. A survey of the general nursing literature reveals that perceived social support can boost the immune system and has a prominent influence on the patient's ability to maintain health promoting behaviors. Levy (1983) also studied compliance and social support, presenting in the work a thorough review of the literature related to social support and its effects on compliance. Social support has been determined to have a direct and powerful relationship with compliance as the result of several factors. First, patients are dependent on their social systems 
to assist them in carrying out compliance behaviors. Second, the beliefs among members in the social system affect compliance. Third, social systems tend to reward appropriate self-care behaviors and repel inappropriate behaviors. Finally, patient characteristics that have been associated with compliance include a good social environment, interpersonal relations, and social participation or integration. In these ways, perceptions, attitudes, and the beliefs of others directly influence the compliance of patients.

\section{Family/Caregivers}

Numerous articles can be found in the nursing literature that describe the family in relation to the cancer experience, a topic previously discussed in the present study. Two studies deserve further explanation. Cassileth, et al. (1985) describe a psychological analysis of cancer patients and their next of kin. The authors attempted to evaluate the interrelationship between the family's and the patient's response to cancer. The patients and their relatives completed the spielberger state Anxiety Scale, the Profile of Mood States, and the Mental Health Indices. Cassileth et al postulated that a supportive family environment assists in the family's ability to deal with a cancer diagnosis. The researchers attempted to validate this premise through a study of 201 cancer patients and their relatives. The resulting data suggested that the 
psychological responses between cancer patients and their relatives were comparable. Similarities were found between cancer patients and their next of kin in each of the diagnostic categories evaluated. The authors found that relatives provide a psychological environment in which the patient reacts and, conversely, that patients influence the level of distress or adaptability exhibited by their relatives. Hence, perceptions and actions of the patient and family have a correlational effect on outcome. Thorne (1985) also studied the family cancer experience. In her interviews she found that families strive to maintain normalcy despite a cancer diagnosis. She further demonstrated that most families had striven to preserve as much normalcy as possible during previous stressful life events, illustrating that families tend to repeat coping strategies that have been used in the past.

Thorne also describes the "meaning dimension" or perceptions cancer families have regarding the disease. Families that perceive cancer as an adaptable experience were found to have better coping strategies overall. In both studies cited here the reciprocal nature of potential influence between the family and the patient was established in the data.

\section{Social Support}

Because it is acknowledged as an important aspect of patient care, social support can be found in all areas of 
the nursing literature. While the concept as it relates to coping in the cancer patient has been previously described in this study, the researcher believes three articles deserve special attention. Wortman (1984) studied social support and the cancer patient. In his extensive review of the literature he found that social support has been demonstrated to play an important role in protecting cancer patients from the effects of stress. Positive interactions as well as perceived positive social interactions were shown to be associated with positive health outcomes. Furthermore, social support has been used as a predictor of adjustment to illness in various longitudinal studies. According to the author, numerous studies also show a strong correlation between social support and adaptation.

Maxwell (1982) studied the use of social networks to help cancer patients maximize support and that social support can act as a buffer to mediate the negative effects of illness. Social support was identified as an important variable in determining how well a person with cancer will be able to cope with his or her illness. Maxwell concludes that social support is essential for coping. In addition, larger social networks with reciprocal links have been found to be associated with a greater degree of perceived support. Maxwell goes on to elaborate on the notion that patients need to feel that they are important providers as well as recipients of support from within their networks. 
Holland and Mastrovitt (1980) studied psychological adaptation to breast cancer, specifically factors that influence adaptation to breast cancer. They found that these factors can be divided into two parameters: one from the patient and one from the disease. The former includes previous psychological adjustment of the patient and her social support, especially that of her significant other. The second parameter describes the state of the disease. A strong support system can counter negative aspects in the disease parameter and thus result in positive adjustment. summary

The conceptual framework of symbolic interactionism serves as a foundation upon which to interpret the concepts under investigation. Symbolic interactionism describes how individuals are in constant interaction with their surroundings. Symbolic interactionism was used as a framework or focus upon which to study perceived meaning, compliance due to perception, family/caregivers and social support when reviewing the related literature. symbolic interactionism was found to be an effective framework upon which to base a study of perceptions, coping and support. 


\section{Chapter 3}

METHODOLOGY

Design

The design of this study was descriptive and correlational. The SIP was used to obtain data that could be summarized and described. This design allowed the researcher to organize data in manageable portions so that specific characteristics could be described. The correlational methodology was chosen to examine the strength of the relationship between the variables of the cancer patient's perceptions and those of the primary caregiver. The researcher also attempted to determine which specific variables demonstrated the greatest influence on overall patient/caregiver responses relating to dysfunction.

\section{subjects/setting}

Inpatient and outpatient cancer patients and their primary caregivers were studied during this research. Subjects were selected on the basis of their willingness to participate in the study, as well as the ability to meet the inclusion criteria. Criteria for inclusion in the study were as follows: (a) the subjects had to be able to read, write, and speak English; (b) the primary caregiver and the cancer patient both had to be present during administration of the questionnaire; (c) the subjects had to be well enough to complete the questionnaire; (d) the cancer patient had to 
be hospitalized on the Oncology Special support Unit; and (e) the cancer patient and the primary caregiver had to be at least 21 years of age.

The study was conducted on the 29-bed inpatient Oncology special support Unit of an acute care hospital. Both inpatient and outpatient cancer subjects receiving treatment were included. With the exception of one, all rooms were single units, thus affording privacy during the interview process.

\section{Human Subjects' Approval}

The study protocol was presented to the Institutional Review Committee (IRC) of the acute care hospital in which the study was conducted. Since the subjects to be investigated included cancer patients, the IRC requested that approval be obtained from the Cancer Care Committee to assure that cancer patients would not be placed in jeopardy. The tool, purpose of the study, population to be studied, risks and benefits to the subjects, and consent format were presented. Risks were described as the potential for subjects to become fatigued while completing a 30 minute questionnaire/interview and the possibility for psychosocial stress due to the personal nature of the questions. Benefits were described as a personally supportive interaction, the potential for the subject to learn something about him or herself, and the potential value of the SIP as an assessment of personal needs in the hospital 
or home. The Cancer Care Committee was assured that participation would be voluntary and that subjects would be informed that refusal to participate would not compromise their care. Subjects would be allowed to stop the questionnaire at any time. In order to maintain patient confidentiality, the physicians on the Cancer Care Committee were not permitted to review the completed questionnaires. However, physicians received the tabulations of the results of the study once it had been completed. Both the Cancer Care Committee and the IRC gave unconditional approval, and written consent was obtained from the IRC (See Appendix B). Final consent was obtained from the Institutional Review Board (IRB) Human subjects at San Jose State University. The purpose of the study, study format, and previous approvals were submitted in written form to the IRB, which was informed that questionnaires would be locked in a secure file and that patient confidentiality would be maintained. The IRB was also assured that the risks to the subjects would be minimal and that subjects would be thoroughly informed of their rights prior to written consent being obtained. Approval to use the SIP on the population described above was obtained.

As an oncology nurse and a nurse manager, the researcher was cognizant of potential for psychological risks to cancer patients. The researcher also had the experience to answer questions posed by the subjects. 
Data Collection

The researcher asked a convenience sample of cancer patients on the oncology special support Unit whether they were willing to participate in a study. The researcher described the study to the cancer patient. If Cancer patients agreed to participate, they were asked to identify a primary caregiver whom the researcher could contact to request inclusion in the study. If the primary caregiver consented to participate, a mutually agreeable time to administer the questionnaire in the hospital was established and informed consent was obtained (See Appendix C). Both members of the dyad answered a biographic questionnaire (See Appendices $D$ and $E$ ) before completing the SIP simultaneously in the presence of the researcher. Discussion during administration of the SIP was limited to the researcher's clarification of questions. Subjects were also instructed to refrain from discussing the SIP with one another. The researcher obtained consent and biographical data before reading introductory statements to the subjects. Administration time was approximately 30 minutes. Data were collected and compared for each cancer patient and primary caregiver.

\section{Instrument}

The researcher contacted Dr. Marilyn Bergner, the developer of the Sickness Impact Profile (SIP), to obtain initial approval to use the instrument (See Appendix F). At 
that time the researcher presented the purpose of the study, the population to be tested, and the correlational design of the research. Thereafter, Dr. Bergner gave written consent to use the SIP (See Appendix G).

The SIP is a behaviorally based measure of sickness related dysfunction, which addresses activities that individuals undertake in carrying on their lives (Bergner, 1978). The instrument is designed to test subjects' perceptions of performance of these activities.

Gilson, Gilson, Bergner, Bobbitt, Kressel, Pollard, and Vesselago (1975) describe the Sickness Impact Profile (SIP) as a measure of behavioral dysfunction in ordinary daily activities. Pollard, Bobbitt, Bergner, Martin, and Gilson (1976) describe the SIP as a behaviorally based measure of the impact of sickness, and Frank-stromborg (1988) describes it as a tool developed to provide a measure of perceived health status that is sensitive enough to detect changes or differences occurring over time or between groups. Ott, Sivarajan, Newton, Almes, Bruce, Bergner, and Gilson (1983) explain that the SIP is valuable in evaluating perceived dysfunction. They used the tool to measure the subjective expression of "feeling better." Deyo, Inui, Leninger, and Overman (1984) found the SIP to be practical, applicable to clinical populations, and comprehensive. McSweeny, Grant, Heaton, Adams, and Timms (1982) describe the SIP as a measure of life quality that was developed as an outcome 
measure for evaluation of treatment.

The original impetus for development of the SIP in 1972 derived from the curiosity of internists who, as Bergner states, desired a quantitative measure of patients' functional abilities. These pioneers were aware that in many instances outcome or improved functional status comprised the goal rather than "cure." Health Maintenance Organizations (HMOs) initially funded the development of the SIP because they were in need of an assessment tool that could measure the health status of a particular population.

Lay and professional opinions were obtained in the development of the SIP. Random patients, health care professionals, and lay individuals divulged information relevant to sickness related dysfunction. More than 1000 forms were collected, grouped, and scaled (Gilson et al., 1975). Pilot testing was administered to 278 subjects, and after subsequent testing in 1973, 1974, and 1976, in addition to revision following each testing, the present SIP was developed. The current SIP has 12 categories whereas the original tool yielded 300 items in 14 categories. Today the SIP is a widely used and well-known tool for studying various populations. Bergner (1978) describes the validity of the SIP, elaborating on construct validity that was demonstrated when the SIP showed the ability to distinguish between subgroups in which prior hypotheses were available. Bergner also describes the relationship of the 
SIP to other measures that assume validity. Heaton, Grant, McSweeny, Adams and Petty (1983) found that validity studies showed the SIP to be a sensitive indicator of the effects of a variety of sickness related conditions. Frank-stromborg (1988) gives a detailed account of the validity of the SIP. She describes its strength and the convergent validity or the ability of different measures of the same trait to correlate highly with the SIP. In addition, discriminant validity is shown since there are higher relationships between the SIP and dysfunction measures versus the SIP and sickness measures. Frank-stromborg (1988) also describes the ability of the SIP to detect low level disability, thus making it a tool that is sensitive to change.

The SIP has been tested against clinical measures on patients with hip replacement, hyperthyroidism, and rheumatoid arthritis. The physical dimension of the SIP was found to correlate to a higher degree than the psychosocial score with these populations (Frank-stromborg, 1988). Bergner, Bergner, and Halstrom (1984) found that the SIP distinguished post myocardial infarction patients from control groups. Deyo et al. (1984) compared the SIP with a physician completed American Rheumatism Association (ARA) functional classification scale, a physician rated seven point change in overall functioning, and a physician rated five point scale of overall change in status on rheumatoid arthritis patients. The SIP was more sensitive than the 
physician completed ARA scale, although the patient self-rating scale was more sensitive than the SIP.

ott et al. (1983) describe a study done by the Seattle/King County Department of Health in post myocardial infarction patients. The researchers determined that the SIP was able to detect changed scores on patients six months after a myocardial infarction in comparison to a control group. In this study, the SIP was unable to establish acceptable discriminate straight scores. Liang, Cullen, and Larson (1982) describe a study between the arthritis impact measurement scale and the $\operatorname{SIP}(\underline{\underline{r}}=.97, \underline{\underline{p}} .05)$. Other arthritis measures have been compared to the SIP and do not show the same extent of correlation, such as the Functional Status Index ( $\underline{\underline{r}}=.62, \underline{\underline{p}} \times .05)$ and the Index of Well-Being $\left(\underline{\underline{c}}=.61, \underline{p}^{<} .05\right)$ (Frank-Stromborg, 1988). Heaton et al. (1983) describe a study completed by the National Heart and Lung Institute in which the SIP was used to differentiate nocturnal oxygen therapy trial (NOTT) patients from chronic obstructive pulmonary disease (COPD) patients. The straight scores demonstrated the expected differences between the groups, while the retest at six months did not show significant differences. Sugerbaker, Barofsky, Rosenberg, and Granola (1982) used the SIP along with the Karnofsky index of daily living and a psychosocial adjustment scale to test limb spared versus limb amputated patients. They found the SIP to be a good indicator and more sensitive with 
hospitalized patients. Finally, McClean, Dickman, and Temkin (1984) found that the SIP was able to distinguish head injury patients from a control group. ott et al. (1983) assert that the validity and reliability of the SIP is well established. Deyo et al. (1984) state that the validity and reliability of the SIP has been carefully tested.

The overall reliability of the SIP is good ( $\underline{I}=.75$ to $.92, \underline{p}<.05)$ (Frank-stromborg, 1988). Bergner (1978) describes the internal consistency of response patterns $(\underline{r}=.94, \underline{p}<.05)$. Pollard et al. (1976) found the SIP to be equally reliable among subjects of different age groups, sexes, educational levels, and levels of dysfunction. This tool was employed by a prepaid group practice, including a nurse practitioner, to assess well adults in a preventative care program (Bergner, 1978). The SIP has been translated into spanish and has been slightly modified to fit British diction. The British model was used at st. Thomas Medical School in London to evaluate the long-term needs of rehabilitation patients (Bergner, 1978). The Veterans Administration in seattle used the sIp to test chronic low back pain patients (Bergner, 1978). It was also used on a population of radiation oncology patients in 1983 by King and Murray, who found the SIP to be an acceptable measure of quality of life.

The current study used the recommended format for 
administration of the SIP. As noted before, the correlational design is a new method for use with this tool. Dr. Bergner is interested in adding the findings here to other studies conducted with the SIP. While use of the SIP constitutes a replication, the correlational design is a pilot.

The SIP is divided into 12 categories with two dimensions: psychosocial and physical (Table 1). Each of these categories describes a particular activity that individuals undertake in order to continue with their lives. Subjects checked specific statements describing the patient at the moment of completing the questionnaire (Conn, Bobbitt \& Bergner, 1978).

Table 1 Sickness Impact Profile Dimensions

\begin{tabular}{|c|c|c|}
\hline Dimension & Category & $\begin{array}{l}\text { Describes Behaviors } \\
\text { Related to: }\end{array}$ \\
\hline Physical & $\begin{array}{l}\mathrm{A} \\
\mathrm{M} \\
\mathrm{BCM}\end{array}$ & $\begin{array}{l}\text { Ambulation } \\
\text { Mobility } \\
\text { Body Care and } \\
\text { Movement }\end{array}$ \\
\hline Psychosocial & $\begin{array}{l}S I \\
C \\
A B \\
E B\end{array}$ & $\begin{array}{l}\text { Social Interaction } \\
\text { Communication } \\
\text { Alertness Behavior } \\
\text { Emotional Behavior }\end{array}$ \\
\hline $\begin{array}{l}\text { Researcher terms } \\
\text { this area } \\
\text { "Personal Habits" }\end{array}$ & $\begin{array}{l}S R \\
E \\
W \\
H M \\
R P\end{array}$ & $\begin{array}{l}\text { Sleep Rest } \\
\text { Eating } \\
\text { Work } \\
\text { Home Management } \\
\text { Recreation and } \\
\text { Pastimes }\end{array}$ \\
\hline
\end{tabular}


The SIP was used as a survey instrument to determine the general health of the cancer patients and, more specificaliy, their perceptions of their situations as compared to those of the primary caregivers' perceptions. Gilson et al. (1975) explain that the perceptions the individual has of his or her own illness has a critically influential role on the impact of illness. They further state that the behavior or performance dimension as perceived by the individual is an appropriate reason to measure outcomes for the following reasons:

1. The behavior of an individual is a manifestation at a given time of the overall impact of illness reflecting both the clinical and subjective dimensions as well as their interactive effects on daily life activities.

2. The effect of sickness on an individual's social, mental and physical activities is perceived and appreciated by both providers and consumers of health services.

3. A measure of behavioral dysfunction, independent of clinical examination, is particularly appropriate in evaluation of health care systems that are responsible for the health maintenance of heterogeneous population groups over extended periods of time (p. 1306).

The SIP is scored by adding predetermined scale values 
for each statement checked and dividing by the maximum possible dysfunction score for that category. The resulting figure is then multiplied by 100 to obtain the category score.

The 12 categories of the SIP include ambulation (A), mobility $(M)$, body care and movement ( $B C M)$, social interaction (SI), communication (C), alertness behavior $(A B)$, emotional behavior (EB), sleep and rest (SR), eating (E), work (W), home management (HM), and recreation and pastimes (RP).

The physical dimension score is calculated by adding the scores for BCM, M, and A categories, while the psychosocial score is derived from the addition of categories $E B, A B, C$, and SI. Once the scores are added for their appropriate dimension, they are divided by the maximum dysfunction score for that dimension and then multiplied by 100. The scores for the remaining categories are always calculated individually. For ease of interpretation the researcher has termed the remaining categories "personal habits."

Code numbers in this study were removed prior to administration of the SIP to assure that subjects would complete the form with integrity. The sIP contains the scoring mechanism. Each statement is followed by a checking line, directly behind which are two sets of numbers in parentheses. The first set indicates the item number and 
the second indicates the scale value for that statement. The upper right hand corner shows the category along with the maximum dysfunction score for that category. In the lower right hand corner of the title page of the SIP are three numbers representing the SIP total possible scale value of 1003, the SD 1 or total possible scale value of the physical dimension of 356.4 , and the SD II or total possible scale value of the psychosocial dimension of 356.7 (See Appendix A).

Analysis Procedures

Compilation of SIP questionnaire results from 60 subjects ( 30 dyads) yielded extensive data. For ease of interpretation the initial raw data were tabulated using a LOTUS spread sheet format. Category, dimension and total SIP scores were then computed for each subject. The individual subject dimension and total SIP scores are presented in Appendix H. The reduction of the data to dimension and category scores enabled the researcher to interpret the initial results as well as to analyze initial correlations.

A correlation matrix comprised of separate total category scores for cancer patients and primary caregivers was established for both the physical and psychosocial dimension as well as the 5 other categories ("personal habits"). Pearson Product Moment Correlation Coefficients were used to determine the extent of relationship present 
between patient and caregiver responses (perceptions of functional status). The biographic variables of age, gender, relationship, education and time since diagnosis were correlated separately with each of the three dimension categories.

Two separate multiple regressions were employed to determine which factors had the greatest influence on the total patient and the total caregiver SIP scores. The 12 patient and 12 caregiver overall category scores (perceptions) were used as independent variables for the multiple regressions.

Rudimentary demographic and SIP calculations also illustrated pertinent findings. A supplementary explanation of procedures used to analyze the data is included in Chapter 4 . 


\section{Chapter 4 \\ FINDINGS AND INTERPRETATION}

This chapter presents the findings and interpretation of the data obtained from the SIP and demographic questionnaires given to cancer patients and their primary caregivers. The study consisted of 30 cancer patients and 30 primary caregivers. Descriptive and correlational findings of the information obtained from the 30 dyads are presented followed by an analysis of the data.

Demographic Characteristics of the Sample

The numbers and percentages of the demographic characteristics of patients and primary caregivers are presented in separate tables. The demographic characteristics of the cancer patients are presented in Table 2 and include: (a) gender, (b) age, (c) educational level, (d) ethnic origin, (e) type of cancer, and ( $f$ ) time since diagnosis. The demographic characteristics of the primary caregivers are presented in Table 3 and include: (a) gender, (b) age, (c) education level, (d) ethnic origin, and (e) relationship to cancer patient.

The sample of cancer patients included 18 females and 12 males. The greatest number of cancer patients were 51-60 years old $(\underline{n}=10)$ followed by 61-70 years $(\underline{n}=7)$. The mean age of cancer patients was 56.3. The youngest cancer patient studied was 23 years and the oldest was 91 years. 
Table 2

Demographic Characteristics of Cancer Patients $\quad(N=30)$

\begin{tabular}{|c|c|c|c|}
\hline Variable & Classification & $\underline{\mathrm{n}}$ & Percent \\
\hline Gender & $\begin{array}{l}\text { Female } \\
\text { Male }\end{array}$ & $\begin{array}{l}18 \\
12\end{array}$ & $\begin{array}{l}60.08 \\
40.0 \%\end{array}$ \\
\hline Age & $\begin{array}{l}20-30 \text { years } \\
31-40 \text { years } \\
41-50 \text { years } \\
51-60 \text { years } \\
61-70 \text { years } \\
71-80 \text { years } \\
81-90 \text { years } \\
91-95 \text { years }\end{array}$ & $\begin{array}{r}2 \\
5 \\
1 \\
10 \\
7 \\
3 \\
1 \\
1\end{array}$ & $\begin{array}{r}6.78 \\
16.78 \\
3.38 \\
33.38 \\
23.48 \\
10.08 \\
3.38 \\
3.38\end{array}$ \\
\hline Education Level & $\begin{array}{l}\text { High School } \\
\text { Graduate } \\
\text { Some College } \\
\text { College Graduate } \\
\text { Masters or higher }\end{array}$ & $\begin{array}{r}10 \\
9 \\
8 \\
3\end{array}$ & $\begin{array}{l}33.38 \\
30.08 \\
26.78 \\
10.08\end{array}$ \\
\hline Ethnic origin & $\begin{array}{l}\text { White } \\
\text { Other }\end{array}$ & $\begin{array}{r}29 \\
1\end{array}$ & $\begin{array}{r}96.78 \\
3.38\end{array}$ \\
\hline Type of Cancer & $\begin{array}{l}\text { breast } \\
\text { leukemia } \\
\text { ovarian } \\
\text { lung } \\
\text { myelodysplasia } \\
\text { lymphoma } \\
\text { colon } \\
\text { stomach } \\
\text { esophageal } \\
\text { testicular } \\
\text { sarcoma } \\
\text { bladder } \\
\text { multiple myeloma } \\
\text { brain } \\
\text { pancreatic }\end{array}$ & $\begin{array}{l}6 \\
3 \\
3 \\
3 \\
3 \\
2 \\
2 \\
1 \\
1 \\
1 \\
1 \\
1 \\
1 \\
1 \\
1\end{array}$ & $\begin{array}{r}20.08 \\
10.08 \\
10.08 \\
10.08 \\
10.08 \\
6.78 \\
6.78 \\
3.38 \\
3.38 \\
3.38 \\
3.38 \\
3.38 \\
3.38 \\
3.38 \\
3.38\end{array}$ \\
\hline $\begin{array}{l}\text { Time since } \\
\text { Diagnosis }\end{array}$ & $\begin{array}{l}\text { Less than } 6 \text { months } \\
6 \text { months to } 1 \text { year } \\
1 \text { to } 5 \text { years } \\
5 \text { years or greater }\end{array}$ & $\begin{array}{r}9 \\
5 \\
13 \\
3\end{array}$ & $\begin{array}{l}30.08 \\
16.78 \\
43.38 \\
10.0 \%\end{array}$ \\
\hline
\end{tabular}


All cancer patients graduated from high school. The largest number of cancer patients $(\underline{\underline{n}}=10)$ list graduating high school as their highest level of education, while subjects with some college $(\underline{n}=9)$ and college degrees $(\underline{n}=8)$ followed closely. Cancer patients in this study were fairly well educated. With the exception of a single subject all other cancer patients describe their ethnic origin as white $(\underline{n}=29)$. There were no Asian, Hispanic or Black subjects. Breast cancer was the most common type of cancer studied $(\underline{\underline{ }}=6)$ followed separately by leukemia $(\underline{n}=3)$, ovarian $(\underline{n}=3)$, lung $(\underline{n}=3)$ and myelodysplasia $(\underline{n}=3)$. There were 15 different types of cancer included in this study. Most cancer patients had been diagnosed between one and five years $(\underline{n}=13)$. The sample also included subjects diagnosed less than six months $(\underline{n}=9)$, subjects diagnosed between six months and one year $(\underline{\underline{n}}=5)$ and five years or greater $(\underline{n}=3)$.

The sample of primary caregivers included an equal distribution of females $(\underline{n}=15)$ and males $(\underline{n}=15)$ (See Table 3). The largest number of primary caregivers were 61-70 years $(\underline{\underline{n}}=9)$. The primary caregiver mean age was 57.2, approximately one year older than cancer patients. The youngest primary caregiver studied was 30 years, while the oldest was 81 years. The educational level of primary caregivers demonstrated that only two did not graduate from high school, while the largest number described high school 
Table 3

Demographic Characteristics of Caregivers $\quad(N=30)$

\begin{tabular}{|c|c|c|c|}
\hline Variable & Classification & $\underline{\mathbf{n}}$ & Percent \\
\hline Sex & $\begin{array}{l}\text { Female } \\
\text { Male }\end{array}$ & $\begin{array}{l}15 \\
15\end{array}$ & $\begin{array}{l}50.0 \% \\
50.0 \%\end{array}$ \\
\hline Age & $\begin{array}{l}26-30 \text { years } \\
31-40 \text { years } \\
41-50 \text { years } \\
51-60-\text { years } \\
61-70 \text { years } \\
71-80 \text { years } \\
81-85 \text { years }\end{array}$ & $\begin{array}{l}1 \\
4 \\
6 \\
5 \\
9 \\
4 \\
1\end{array}$ & $\begin{array}{r}3.38 \\
13.38 \\
20.08 \\
16.78 \\
30.08 \\
13.38 \\
3.38\end{array}$ \\
\hline Education Level & $\begin{array}{l}\text { Did not graduate } \\
\text { High school } \\
\text { High School } \\
\text { Graduate } \\
\text { Some College } \\
\text { College Graduate } \\
\text { Masters or higher }\end{array}$ & $\begin{array}{r}2 \\
10 \\
6 \\
10 \\
2\end{array}$ & $\begin{array}{r}6.78 \\
33.3 \% \\
20.0 \% \\
33.38 \\
6.7 \%\end{array}$ \\
\hline Ethnic origin & $\begin{array}{l}\text { White } \\
\text { Other }\end{array}$ & $\begin{array}{r}29 \\
1\end{array}$ & $\begin{array}{r}96.7 \% \\
3.3 \%\end{array}$ \\
\hline $\begin{array}{l}\text { Relationship to } \\
\text { Cancer Patient }\end{array}$ & $\begin{array}{l}\text { Spouse } \\
\text { other relative } \\
\text { Friend } \\
\text { significant other }\end{array}$ & $\begin{array}{r}19 \\
5 \\
4 \\
2\end{array}$ & $\begin{array}{r}63.38 \\
16.78 \\
13.38 \\
6.7 \%\end{array}$ \\
\hline
\end{tabular}

graduate $(\underline{n}=10)$ or college graduate $(\underline{n}=10)$ as their highest level of education. As with cancer patients, no caregivers described their ethnic origin as Asian, Hispanic or Black. The largest number of primary caregivers described themselves as white $(\underline{n}=29)$. Most primary caregivers were spouses to cancer patients $(\underline{n}=19)$. Significant other $(\underline{n}=2)$ and friend $(\underline{n}=4)$ 
represented the smallest sample of relationships to cancer patient.

Sixty subjects ( 30 dyads) afforded an acceptable sample for the study. This sample included a fairly equal number of male and female subjects, as well as a variety of types of cancer and a range of time since cancer diagnosis. The population studied included several age groups and educational levels, although most subjects were middle-age and well educated.

Explanation of the Correlational statistics Pearson's Product Moment Correlation Coefficients were calculated to determine the extent of the relationship between cancer patient perceptions and caregiver perceptions related to functional status. Cancer patient and caregiver category scores were compared to each other within both the physical and psychosocial dimension, as well as the area termed "personal habits." This yielded three correlation matrices which are presented in Tables 4, 5 and 6 .

The Pearson's Product Moment Correlation Coefficients are displayed as the upper number in each of the pairs of data presented in the three correlation matrices. For correlation coefficients which were not significant results were not included in the matrices.

\section{Physical Dimension Correlations}

The physical dimension of the SIP consists of three categories: (a) ambulation, (b) mobility, and (c) body care 
and movement. Patient and caregiver responses for each of these categories were compared to each other to determine the degree of association. The category responses (perceptions) were compared to determine the similarity of patient and caregiver opinions of physical functional status.

All category correlations presented in the physical dimension matrix (Table 4) yielded strong correlation coefficients ranging from $\underline{\underline{r}}=.57$ to $\underline{\underline{r}}=.81$ with $\mathrm{p}$ levels of $<.01$. This indicates a significant association between patient and caregiver perceptions of physical limitations. Caregivers indicated a higher level of dysfunction than patients in their perceptions of the cancer patients' ability to perform ambulation and mobility activities. Cancer patients perceived a higher level of functional disability than caregivers regarding body care and movement.

The strongest correlation ( $\underline{r}=.81, \underline{p} .01$ ) was found to exist between the patients' and caregivers' perceptions of body care and movement abilities. Considering the personal and dependency nature of the questions in this category, this finding should not be surprising. Most of these activities required caregiver involvement. (For example, question 14 discusses requiring assistance in bathing).

The caregivers' perception of mobility demonstrated the weakest relationships in the physical dimension when 


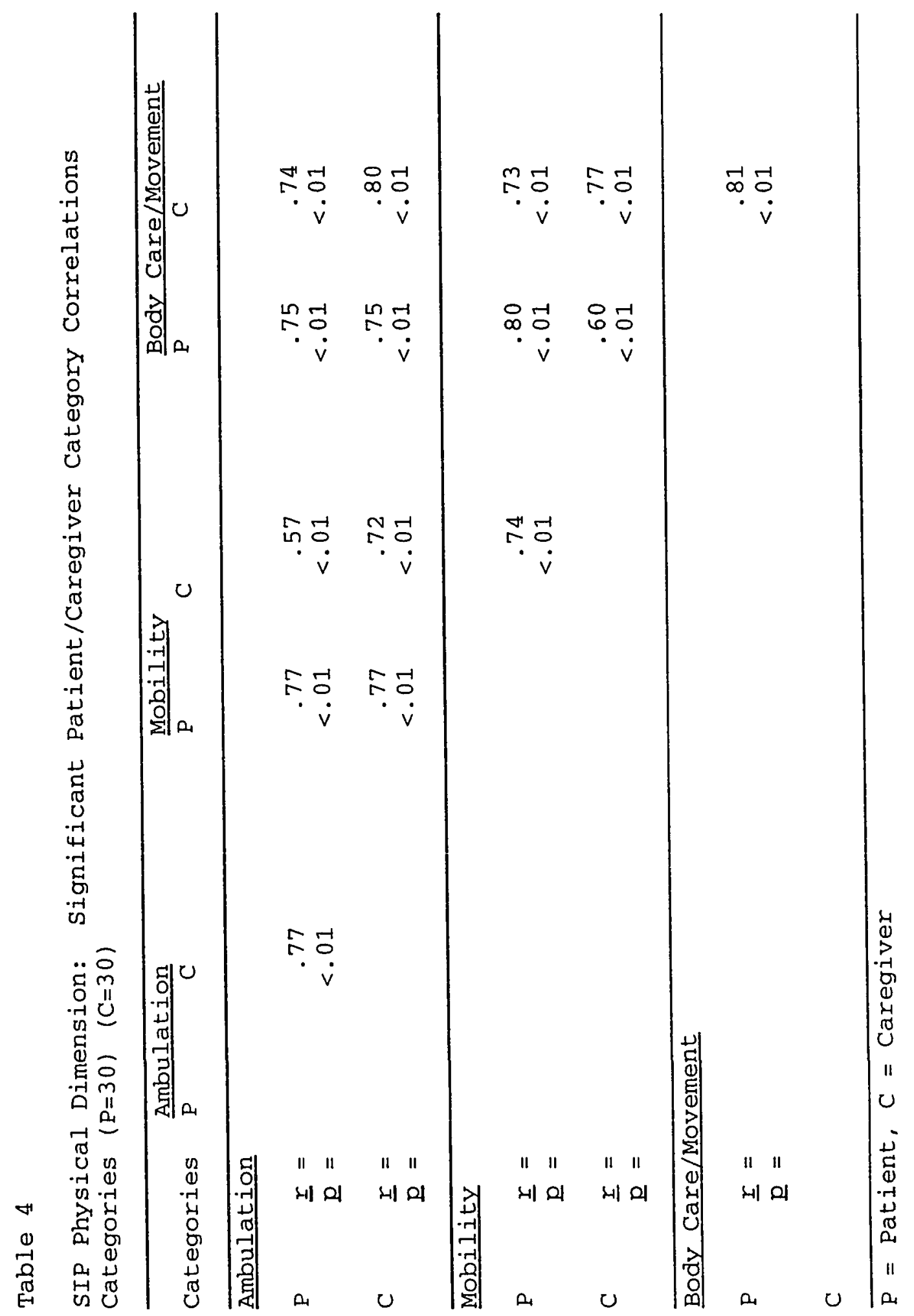


compared to the patients' perception of ambulation ( $\underline{r}=.57$, $\underline{2} .01$ ) and the patients' perception of body care and movement $(\underline{\underline{x}}=.60, \underline{p}<.01)$. The highest level of dysfunction perceived by caregivers in this dimension was in the category of mobility. The lowest levels of dysfunction perceived by patients were in the categories of ambulation and body care and movement, although caregivers rated ambulation higher. This contributed to the aforementioned finding.

The physical dimension category computations yielded the strongest and most consistent correlations among the three matrices presented. This fact may be due to the overt nature of physical limitations. Dysfunction in this area was expected to be easily recognizable.

Psychosocial Dimension Correlations The psychosocial Dimension of the SIP includes the categories: (a) social interaction, (b) communication, (c) alertness behavior, and (d) emotional behavior. Patient and caregiver responses for each of these categories were compared to each other to determine if patient and caregiver perceptions of psychosocial activities, as related to functional status, were associated. With the exception of communication, all other category correlations presented in the psychosocial dimension matrix (Table 5) demonstrated strong correlation coefficients ranging from $\underline{r}=.51$ to $\underline{\underline{r}}=.84$ with $\underline{p}$ levels $<.01$. Excluding communication, an 


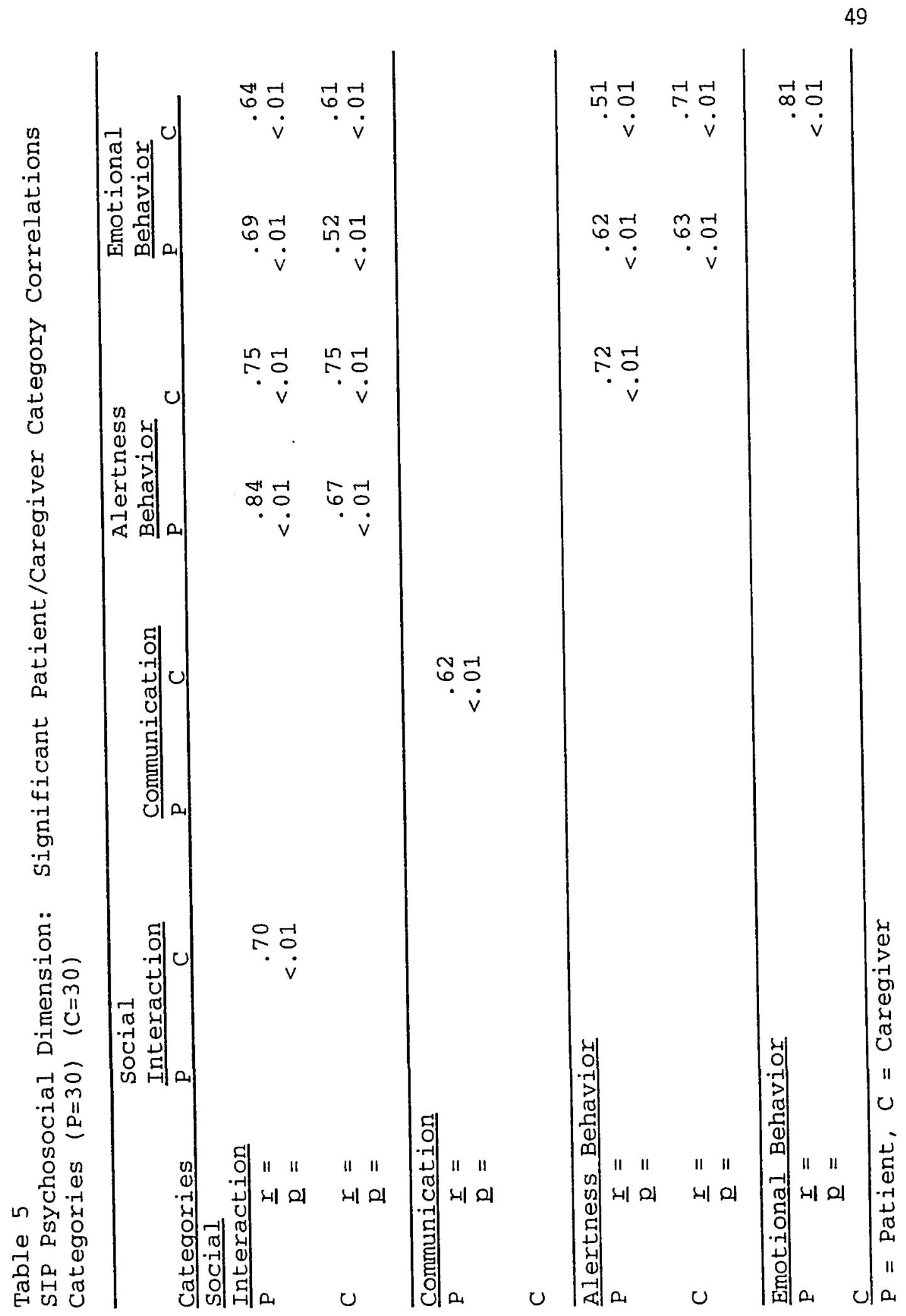


association between patient and caregiver perceptions of functional status, as related to the psychosocial dimension, were evident. Caregivers perceived a higher level of patient functional disability than did cancer patients in each of the psychosocial categories measured.

Unlike other category correlations within this dimension, communication demonstrated only one significant result when compared to other psychosocial categories. Patient and caregiver perceptions of communication were congruent when compared $(\underline{\underline{x}}=.62, \underline{\mathrm{p}}<.01)$, which may be due to the fact that patients and caregivers are "expected" to communicate with each other. The remaining 12 situations in which communication was compared reported no significance.

The SIP questions relating to communication lean toward the physical ability to speak and write, rather than the ability to exchange concepts and feelings. This may have contributed to 43 subjects, ( 20 dyads and three individuals) not checking any of the items in this category as an indication of no dysfunction whatsoever. Overall, both patients and caregivers perceived little dysfunction in communication.

\section{"Personal Habits" Correlations}

The SIP recognizes two dimensions which include a total of seven categories. The remaining five categories are always calculated separately. Because the research was 
correlational in nature, the researcher did not exclude categories which were not included in the two dimensions. A correlation matrix of these five categories ("personal habits") was established to determine if there was any relationship among them. There were some significant statistical findings (Table 6).

The categories of (a) sleep/rest, (b) eating, (c) work, (d) home management, and (f) recreation and pastime comprise "personal habits". Although dissimilar in title, the categories exhibited a relationship to each other reinforcing the previous findings of patient and caregiver cohesiveness of perceptions of functional status.

Patients perceived a higher level of dysfunction than caregivers in the categories of work and recreation and pastimes. Caregivers perceived a greater degree of patient functional disability in the categories of sleep/rest, eating, and home management.

All "personal habits" categories, excluding work, demonstrated some level of significance $(\underline{E}=.34$ to $\underline{\underline{r}}=.87$ with $\underline{\underline{p}}$ levels $(.04)$. This matrix, although not as significant as the other two matrices, did produce findings relevant to the study.

The questions relating to the category of work by far generated the most procedural inquiries. On page 17 of the SIP questionnaire the format changes so that subjects were instructed to skip questions if they answered yes or no to a 


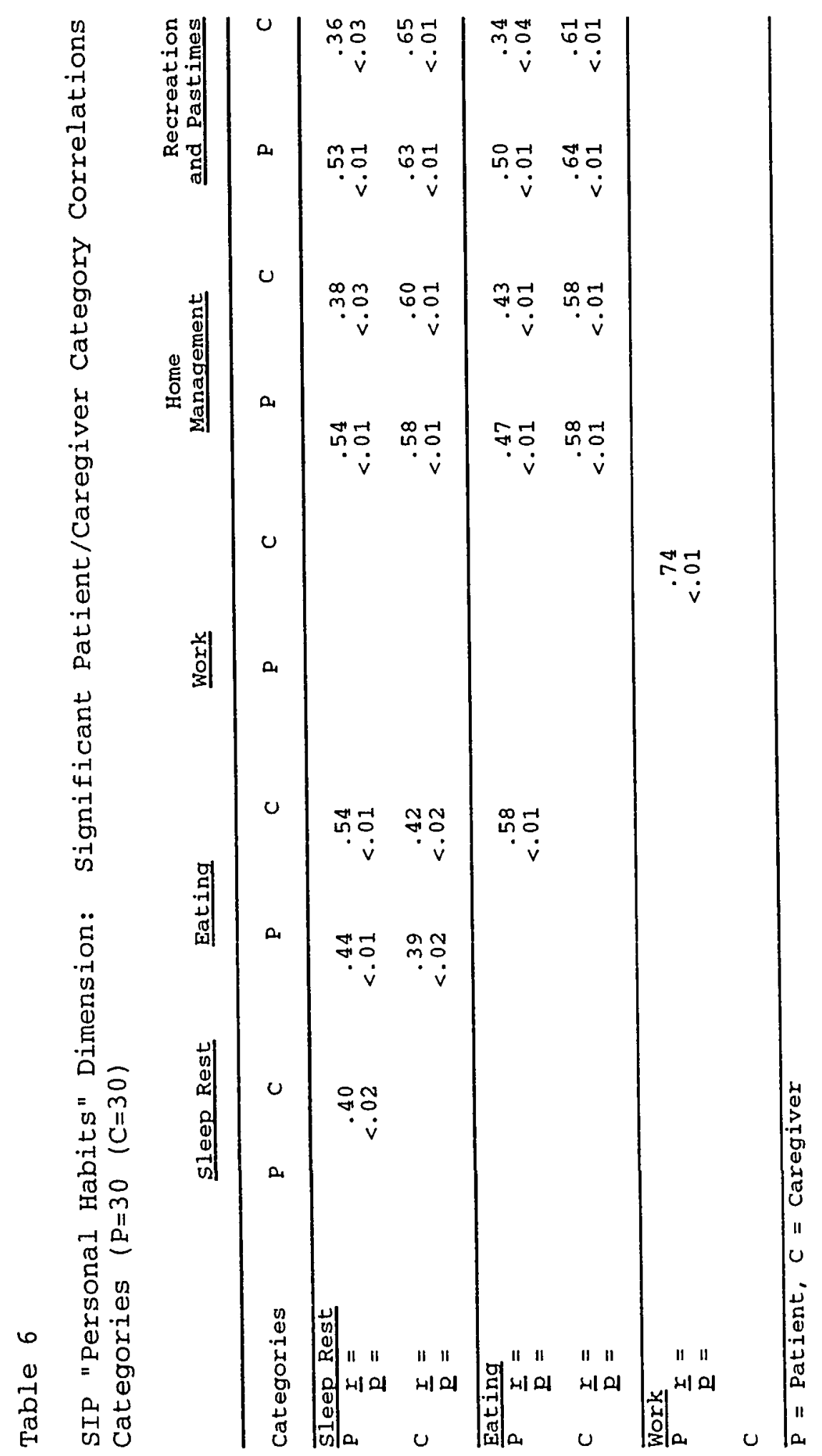




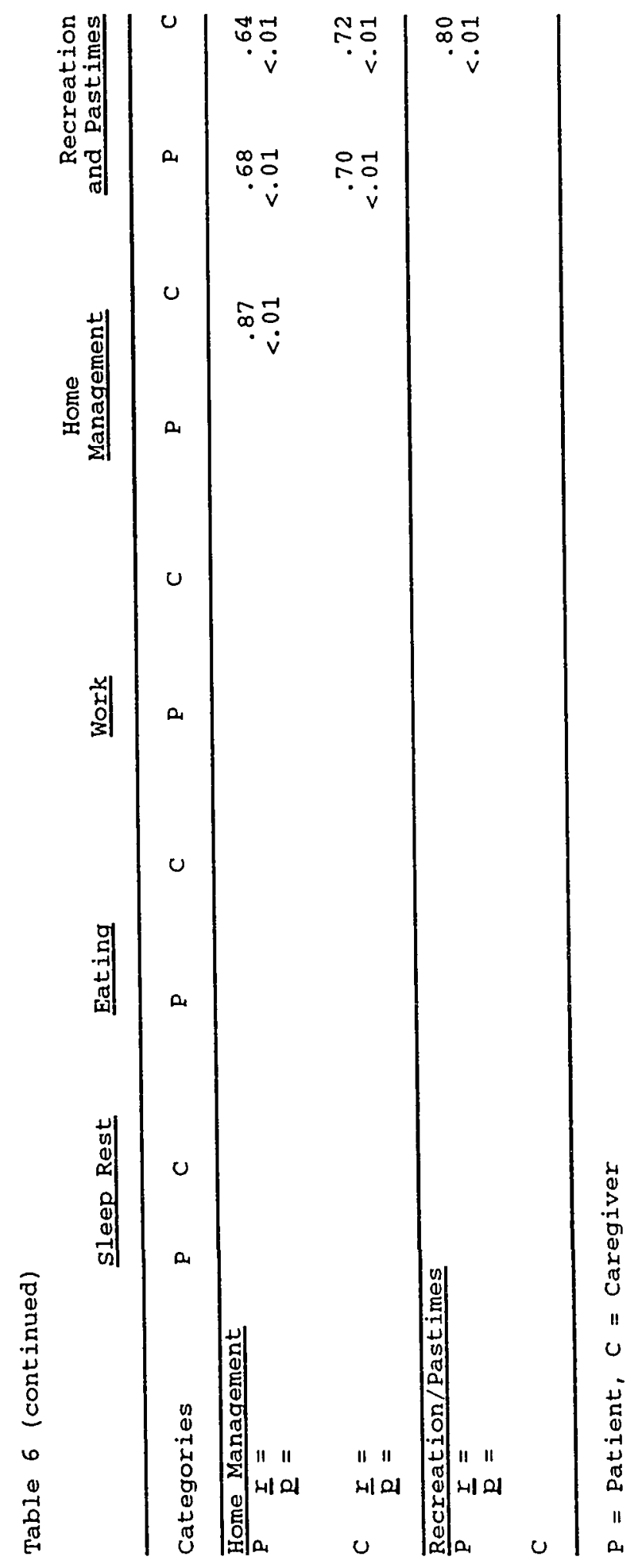


specific question. Prior to this, subjects had been instructed never to answer yes or no, but to check items that described the patient at that particular moment. Question 1 of the work category ("I am not working at all") was statistically adjusted by the SIP developers to take into account the fact that when this item is checked no other scores are possible in this category. Retirees, homemakers and subjects who had never worked had the most difficult time responding, as they felt the work questions were not comprehensive enough to include them.

The one significant statistic in the work category was between patient and caregiver ( $\underline{r}=.74, \underline{p}<.01)$. This may be attributable to the clarification of work questions in the presence of both subjects, as well as to the adjustment in statistical calculation made by the developers of the SIP.

Thus, the findings relating to the aforementioned matrices relating to research question 1 (similarity of perceptions of sickness related dysfunction in cancer patients) demonstrate that overall similarities and differences exist. As described in further detail in the scope and limitations, the correlational design of the study, homogeneous nature of the sample, and cohesiveness within the dyads contributed greatly to the extent of significance of patient/caregiver similarities of perception. When the overall Sickness Related Dysfunction 
scores of patients and caregivers were compared, results were fairly similar indicating moderate dysfunction in the cancer patient. Cancer patients rated higher dysfunction than caregivers in the categories of body care and movement, work, and recreation and pastimes. Caregivers rated higher levels of dysfunction than cancer patients in the categories of ambulation, mobility, social interaction, communication, alertness behavior, emotional behavior, sleep/rest, eating and home management. It is important to note that patient/caregiver differences in perceptions of functional status are evident when individual category perceptions are examined. However, when the total SIP score is calculated there is a congruency of patient/caregiver perceptions because the average of the patient category scores as well as the average of the caregiver category scores demonstrated overall moderate dysfunction.

\section{Biographic Correlations}

The variables: (a) age of patient, (b) age of caregiver, (c) gender of patient, (d) gender of caregiver, (e) relationship between patient and caregiver, (E) educational level of patient, (g) educational level of caregiver, and ( $h$ ) time since diagnosis were correlated to each of the three matrices to determine association. A few correlations demonstrated significance. The majority appeared to have no relationship to categories (perceptions) measured. 
The only biographic correlations within the physical dimension demonstrating any degree of significance occurred in the patient's perception of body care and movement. The education of the patient $(\underline{r}=-.33, \underline{p}<.04)$ and the time since diagnosis $(\underline{\underline{x}}=.42, \underline{p}<.02)$ indicated some relationship to body care and movement as perceived by the patient.

The findings demonstrated that the less educated the patient, the more dysfunction he/she perceived in body care and movement activities, which may be related to lack of knowledge regarding sickness related dysfunction. Conversely, the longer the time since diagnosis, the less the patient perceived significant disability in body care and movement activities, which may relate to adjustment.

Within the psychosocial dimension biographic data generally did not correlate with the categories although a higher percentage of significant findings resulted. Age of the patient exhibited a slight relationship to caregiver's perception of communication $(\underline{r}=.32, \underline{p}<.05)$ and alertness behavior ( $\underline{\underline{r}}=-.33, \underline{\underline{p}} \times .04)$, as well as the cancer patient's perception of social interaction $(\underline{\underline{E}}=-.32$, p (.05). Gender of the patient was associated with both the patient's $(\underline{\underline{r}}=.31, \underline{\underline{p}}<.05)$ and caregiver's $(\underline{\underline{\varepsilon}}=.34$, $\mathrm{p}<.04)$ perception of communication. Gender of the caregiver only related to the patient's perception of alertness behavior $(\underline{\underline{E}}=.31, \underline{\mathrm{p}} \mathbf{0 5})$. 
The findings demonstrated that increased patient age is associated with perceived positive communication with the primary caregiver, perceived decreased alertness behavior and perceived decreased social interaction which may be related to older patients having a long term relationship with their primary caregiver, as well as decreased alertness behavior and social interaction associated with the process of aging and isolation.

similar to the other two matrices the "personal habits" matrix demonstrated inconsequential results when biographic data were compared. The age of the patient showed a relationship to the patients' responses to the work category $(\underline{r}=-.41, \underline{p}<.02)$. Age of the caregiver was related to both the patients' $(\underline{r}=-.40, \underline{p}<.02)$ and caregivers' $(\underline{\underline{x}}=-.47, \underline{p}<.01)$ responses to the work category. Gender of the caregiver showed some degree of association with both the patients' $(\underline{r}=.33, \underline{p}<.04)$ and caregivers' $(\underline{r}=.34$, p .04 ) perceptions of eating. The only other connection within the "personal habits" area was found between the patient/caregiver relationship and the patients' responses to work $(\underline{\underline{\varepsilon}}=.54, \underline{\mathrm{p}} .01)$.

The findings demonstrated that the older the patient and/or caregiver the greater the perception of increased dysfunction in relation to work. This may be attributable to the fact that many individuals choose to decrease work time and/or retire for reasons other than illness as they 
become older.

The data relating to research question 2 (biographic variables correlation to perceptions of dysfunction) appeared to have little relationship to patients' and caregivers' perceptions of dysfunction. The variables of gender, age, educational level, relationship and time since diagnosis demonstrated only fragmented significant correlations, which in most cases may be due to factors other than cancer.

\section{Other Significant Findings}

The total possible SIP score is 1003. The mean score for the population studied was 296 . This represented a mean score for patients of 282.8 and 309.2 for caregivers. The group studied reported only moderate dysfunction. Dimension and total SIP scores are reported in Appendix $H$.

In response to research question 3 (number of patients/caregivers perceiving greatest dysfunction) the researcher's findings establish that caregivers $(\underline{\underline{ }}=19)$ tended to perceive the cancer patients' situation in relation to functional status as more disabling than did cancer patients themselves $(\underline{\underline{n}}=11)$ although patient and caregiver overall scores were fairly close.

$$
\text { Multiple Regression }
$$

Stepwise multiple regressions were employed to determine which patient and caregiver perceptions related to functional status contributed most to the overall patient 
SIP score, as well as to the overall caregiver SIP score.

Two separate multiple regressions were undertaken.

Total Patient SIP Score Multiple Regression

The total patient SIP score was studied in relation to

the 12 patient and 12 caregiver category scores. Variation in the total patient SIP score was anticipated to be a function of specific category scores (perceptions).

The $\underline{F}$ ratio for this statistical test was 21558.94 with the degree of freedom for regression 24 and residual 5 . The extensive number of independent variables (24 category scores) measured in relation to the dependent variable of overall patient SIP score, as well as the sizeable numbers included in the computation, yielded the large F ratio.

Table 7 lists the beta weights and significant $t$ values for the independent variables. Beta weights indicate how well a specific variable (category perception) can predict the overall patient SIP score.

of the 24 category perceptions measured, 12 demonstrated significance. As expected, patient category scores demonstrated the greatest relationship to the overall patient SIP score. Of interest was the fact that only patient category scores demonstrated any significance when results were analyzed.

The patients' perception of work with a beta weight of .193 and a significant $t$ value of 56.516 demonstrated the most influence on the total patient SIP score. This was 
Table 7

Total Patient SIP Score Multiple Regression

\begin{tabular}{llll}
\hline Variable & Beta & $t$ & Significance of $t$ \\
\hline Work (P) & & & \\
Hame Management (P) & .193 & 56.516 & $<.01$ \\
Recreation/Pastimes (P) & .167 & 20.734 & $<.01$ \\
Alertness Behavior (P) & .154 & 22.306 & $<.01$ \\
Emotional Behavior (P) & .149 & 20.128 & $<.01$ \\
Sleep/Rest (P) & .145 & 27.551 & $<.01$ \\
Body Care/Movement (P) & .137 & 23.049 & $<.01$ \\
Mobility (P) & .130 & 19.631 & $<.01$ \\
Ambulation (P) & .105 & 15.950 & $<.01$ \\
Social Interaction (P) & .101 & 21.304 & $<.01$ \\
Eating (P) & .097 & 12.637 & $<.01$ \\
Communication (P) & .067 & 17.332 & $<.01$ \\
& .063 & 12.393 & $<.01$ \\
\hline
\end{tabular}

P $=$ Patient

closely followed by the patients' perceptions of home management, recreation and pastimes, alertness behavior and emotional behavior. The least significant influence was demonstrated in the area of the patients' perception of communication.

The high level of influence exhibited by the patients' perception of work may have been due to the researcher's adjustment in statistical calculation. The patient sample included a number of individuals who were not working for reasons other than sickness related dysfunction. This may also have contributed to the results.

The patients' perception of home management demonstrated a predictive value on the overall patient SIP score. Patients perceived severe dysfunction in home management activities with caregivers scoring this category 
even higher. The fact that $63 \%$ of the dyads were spouses indicates that most of the patients were living with caregivers who probably assumed the home management responsibilities.

of the 12 categories measured, recreation and pastimes was the category in which patients perceived the greatest dysfunction. This is understandable given the psychological and physical implications of a cancer diagnosis.

Emotional behavior and alertness behavior were the two category scores demonstrating the most dysfunction in the psychosocial dimension as perceived by patients. The questions in these categories address the internal psychological aspects of the diagnosis, which are usually not discernable by those other than family. It is interesting to note that caregivers rated every psychosocial category at a higher dysfunction level than patients, and these two categories were perceived by the caregivers to be the areas of greatest disability.

of the significant findings, communication as perceived by the patient demonstrated the least influence on the overall patient sIP score. This finding can be attributed to the low level of disability perceived by patients for this category, as well as the cohesiveness of patient/caregiver perceptions related to communication. As previously stated, patients and caregivers are expected to communicate. 
Total Caregiver SIP Score Multiple Regression

The total caregiver SIP score was studied in relation to the 12 patient and 12 caregiver category scores. The caregivers' total SIP score was an overall reflection of the caregivers' perception of the cancer patients' situation. Variation in the total caregiver SIP score was anticipated to be a function of specific category scores (perceptions). The researcher employed a multiple regression test in order to determine which patient and caregiver category perceptions had the greatest influence on the overall caregiver SIP score. The $\underline{E}$ ratio for this statistical test was 42297.02 with the degree of freedom for regression 24 and residual 5. As described in the total patient SIP score multiple regression, the extensive computations yielded the large $\underline{F}$ ratio.

Table 8 lists the beta weights and significant $t$ values for the independent variables. These beta weights indicate category perception influence on the overall caregiver SIP score.

of the 24 categories measured, 17 demonstrated significant results, five of which were also included as patient category perceptions. These five patient categories include: (a) recreation and pastimes, (b) home management, (c) mobility, (d) body care and movement, and (e) emotional behavior. The greatest dysfunction perceived by patients in the "personal habits" dimension were in the areas of 
Table 8

Total Caregiver SIP Score Multiple Regression

\begin{tabular}{lccl}
\hline Variable & Beta & $\underline{t}$ & Significance of $t$ \\
\hline Home Management (C) & .176 & 34.662 & $<.01$ \\
Alertness Behavior (C) & .161 & 47.083 & $<.01$ \\
Work (C) & .156 & 43.381 & $<.01$ \\
Body Care/Movement (C) & .127 & 16.726 & $<.01$ \\
Mobility (C) & .123 & 32.121 & $<.01$ \\
Social Interaction (C) & .116 & 31.418 & $<.01$ \\
Sleep/Rest (C) & .114 & 36.909 & $<.01$ \\
Emotional Behavior (C) & .108 & 24.858 & $<.01$ \\
Recreation/Pastimes (C) & .103 & 20.945 & $<.01$ \\
Ambulation (C) & .082 & 12.326 & $<.01$ \\
Eating (C) & .078 & 26.603 & $<.01$ \\
Commmication (C) & .060 & 22.802 & $<.01$ \\
Recreation/Pastimes (P) & .020 & 4.041 & $<.01$ \\
Hame Management (P) & -.019 & -3.242 & $<.03$ \\
Mobility (P) & -.013 & -2.799 & $<.04$ \\
Body Care/Movement (P) & .013 & 2.721 & $<.05$ \\
Emotional Behavior (P) & .011 & 2.959 & $<.04$ \\
\end{tabular}

$\mathrm{P}=$ Patient, $\mathrm{C}=$ Caregiver

recreation and pastimes and home management. In the

psychosocial dimension the greatest patient perceived

dysfunction was identified as emotional behavior. In the

physical dimension patients perceived greatest dysfunction

in mobility activities. The one exception was body care and movement, the only category in the physical dimension where patients rated greater dysfunction than caregivers. This may attribute to the aforementioned findings.

The caregivers' perception of home management with a beta weight of .176 and a significant $\underline{t}$ value of 34.662 demonstrated the most influence on the caregivers' overall SIP score. This was closely followed by the caregivers' 
perceptions of alertness behavior and work.

These findings are consistent with the total patient SIP score multiple regression findings. The rationale for the influence of home management, alertness behavior and work perceptions on the overall SIP score is the same. of the 12 significant caregiver perceptions, communication demonstrated the least influence on the overall caregiver SIP score. This correlates with the factors addressed in the patient overall sIP multiple regression.

The multiple regression analyses enabled the researcher to determine which specific patient/caregiver perceptions exerted the greatest influence on patients ' and caregivers' overall perception of dysfunction (research question 4).

The total patient SIP score was influenced most by work, followed by home management, recreation and pastimes and alertness behavior. The total caregiver SIP score was influenced most by home management, followed by alertness behavior and work. The statistical adjustment of the work category may have skewed its weighting in overall SIP scores. Both total patient and caregiver SIP scores were influenced greatly by home management and alertness behavior perceptions. Patient perceptions of recreation and pastimes also demonstrated significant influence on the overall patient SIP score, while the same result was not seen in the 
overall caregiver SIP score. Home management and alertness behavior deserve particular attention, as they demonstrate significant influence on both the overall patients' and the overall caregivers' perceptions of functional status. 
Chapter 5

DISCUSSION

Summary of study

The researcher undertook an extensive review of related literature in order to provide a detailed background of the importance of perceptions, social support and the primary caregiver role. The conceptual framework of symbolic interactionism provided the foundation for a study which describes perceptions. Patient and caregiver responses to a questionnaire measuring perceptions of functional status provided the data for correlation. Patient and caregiver category perceptions were tabulated and analyzed to determine similarities as well as influence on overall patient and caregiver total dysfunction scores.

Comparison of Findings to Literature Lindsey, Ahmed, and Dodd (1985) and Lindsey, Dodd and Chen (1985) stress the importance of social support in coping with a cancer diagnosis. Both articles determined that the family had a featured role in this social support. A similar study by Kesselring, Dodd, Lindsey and Strauss (1986) using symbolic interactionism as a conceptual framework supported these findings. The researcher likewise determined that most cancer patients identified a family member as a primary caregiver. This study was based on the the conceptual framework of symbolic interactionism and the 
results of this study support the research described within this paragraph.

Musci and Dodd (1990) described cancer as a family experience. They determined that family members and patients share similar coping strategies. The researcher found that, since most primary caregivers are family members, cancer affects the family and that patients and caregivers share similar perceptions.

Cassileth, et al. (1985) conducted a psychological analysis of cancer patients and their relatives. They found similarities in the patients' and families' responses to cancer. Thus, they shared similar perceptions. The researcher also determined that overall similarities in patient/caregiver perceptions existed.

\section{Conclusions}

Cancer is affecting more people today than ever before. Early screening, a greater variety of treatment options, and an aging population have increased the number of people living with cancer as a chronic illness. The shift of cancer care to the home has broadened the impact of the disease on primary caregivers and social systems. Treatments which may cure the patient or prolong life can cause troublesome physical disabilities and psychosocial dysfunction. It has been demonstrated that social support influences cancer patients' perception of their diagnosis and assists them in coping with the trials associated with 
the disease.

This study investigated similarities and differences of perception between the patient and caregiver relating to functional status. The population studied demonstrated perceptions of moderate overall dysfunction in the cancer patient.

Although correlations existed within each of the three dimensions and overall scores were similar, there were differences of note. Caregivers saw the cancer patients' situation as more disabling as compared to the patients' self report. Caregivers rated overall categories higher in sickness related dysfunction than did patients: psychosocial 100\%, physical 66\%, "personal habits" $60 \%$.

The only category in the physical dimension in which patients indicated more dysfunction than caregivers was body care and movement, whereas caregivers manifested perceptions of greater dysfunction in the categories of ambulation and mobility than patients.

The only categories in "personal habits" where patients indicated greater disability than caregivers were work and recreation and pastimes. Caregivers scored greater perceptions of dysfunction than patients in the categories of sleep/rest, eating, and home management.

The three SIP dimension correlation matrices yielded significant findings. The physical dimension matrix demonstrated the strongest correlations. The researcher 
attributes this to the fact that physical characteristics such as ambulation, mobility and body care and movement are obvious to both patient and caregiver and are easily measurable.

The psychosocial dimension, with the exception of communication, yielded significant correlations. This correlation matrix did not demonstrate the same degree of significance as the physical dimension. The researcher ascribes these findings to the fact that the caregivers' perceptions of dysfunction in this dimension were greater than those of patients. Psychosocial characteristics are not as easily measurable as physical characteristics. The caregiver may be experiencing some personal psychosocial dysfunction due to the cancer diagnosis and care of the patient and may be displacing these feelings, thus rating dysfunction high. Conversely, the patient may be unaware of personal psychosocial dysfunction due to denial or suppression, thus causing a low perception of dysfunction. The "personal habits" category correlations yielded some level of significance. This area was an untested dimension and was comprised of a mixture of unrelated activities. However, the researcher considers the findings valuable to this study.

Multiple regression analyses were implemented to determine which of the specific category perceptions had the most influence on the overall patient and the overall 
caregiver total dysfunction scores. The specific category perceptions having the most influence on the overall patient total dysfunction score were work, home management, recreation and pastimes and alertness behavior. The specific category perceptions having the most influence on the overall caregiver total dysfunction score were home management, alertness behavior, and work.

The influence of work can be attributed to scoring mechanisms, as well as age of the sample. Both patients and caregivers described severe dysfunction in the home management category. This may be due to the fact that most of the patients studied resided with the caregiver, who in all probability assumed the burden of home management. The nature of the questions in the category of alertness behavior addressed the internal psychological aspects of the diagnosis. The influence on the overall scores is most likely a result of the perception of the patient's inability to perform home management and other daily functions. The researcher described the importance of the congruency of patient/caregiver perception in relation to functional status. Research indicates that patient and caregiver perceptions are valuable in coping and support. They should be recognized by health care workers as integral elements of patient care.

Assessment of caregiver and patient functional status perceptions and clarification by health care workers of 
misconceptions can support effective communication between patient and caregiver to promote perception congruency.

The findings of this study illustrate congruency of patient/caregiver perceptions. Since previous studies have determined that perceptions affect outcomes, appropriate congruent positive perceptions should be nurtured.

\section{Scope and Limitations}

Since the ability to speak, read and write English was a requirement of the study, certain ethnic groups, indigent or illiterate clients may have been excluded. Being well enough to complete the questionnaire was another requirement of this study which may have excluded individuals who were chronically or acutely ill. Some individuals were excluded from this study due to the fact that it was difficult to arrange a convenient time when both members of the dyad could be present in order to complete the questionnaire. Cancer clients who were under the age of 21 or who were unable to identify a significant other were also excluded from this study.

The total sample was tested in the hospital setting. This setting, in itself, may have been a confounding variable in relation to the SIP. The setting may have reminded subjects of the presence of cancer. Subjects may have been temporarily nauseated or sick due to treatments for cancer which they were receiving in the hospital. This researcher attempted to avoid all unnecessary distractions 
and to test subjects at the most opportune time in terms of physical limitations and hospital routines.

All subjects with the exception of two described their ethnic origin as white. This makes it difficult to generalize cultural influences in relation to perceptions of a cancer diagnosis. Most cancer patient/primary caregiver dyads studied were spouses $(\underline{n}=19)$ followed by other relatives $(\underline{n}=5)$, which makes it difficult to generalize the findings to caregiver relationships other than close or spousal relatives.

The subjects were homogeneous and the dyads were cohesive in nature. This is due to the fact that the more educated, functional dyads were most willing to participate, as well as most easily approached. The researcher acknowledges that she approached the most familiar and willing participants, which presented a limitation. Self report also may have presented bias.

The quantity of variables were considerable in relation to the 30 dyads studied. The number of different types of cancers included in the study also was sizable in relation to the subject sample. These two factors make it difficult to generalize the findings.

\section{Recommendations}

1. Since the correlational design using the SIP appears to measure and obtain subjective as well as objective data, more replication studies should be done. 
2. A Karnofsky scale used (rating of physical ability) in conjunction with the SIP could determine objective physical data related to functional status, which then could be compared to patient/ caregiver responses to determine congruency.

3. Psychological testing of patients and caregivers in conjunction with administration of the SIP, with particular attention devoted to coping and social support, would validate the psychosocial perceptual responses of subjects.

4. The sample could be expanded to include various ethnic and social groups, dysfunctional dyads, and unrelated patient/caregiver dyads.

5. A similar study could be conducted in the home environment.

\section{Nursing Implications}

This study demonstrates that cohesiveness of perceptions in the cancer family is necessary for positive coping. Nurses usually assess and encourage realistic, positive perceptions when dealing with patients, however, in order to foster cohesive perceptions in the cancer family, nurses should be cognizant of the importance of evaluating and supporting the same realistic, positive caregiver perceptions. These perception similarities between caregivers and cancer patients related to functional status lead to positive outcomes. 
REFERENCES 
References

Andolsek, K. M., Clapp-Channing, N. E., Gehlbach, S. H., Moore, I., Proffitt, V. S., Sigmon, A., \& Warshaw, G. A. (1988). Caregivers and elderly relatives:

The prevalence of caregiving in a family practice. Archives of Internal Medicine, 148, 2177-2180.

American Cancer Society (1991). Cancer facts \& figures (90-500 M-No. 5008.91-LE). Atlanta, Georgia: National Headquarters, American Cancer Society, Inc.

Bergner, M. (1978). The sickness impact profile: A brief summary of its purpose, use, and administration.

University of Washington: Department of Health Services. Bergner, L., Bergner, M., \& Hallstrom, A. P. (1984). Health status of survivors of out-of-hospital cardiac arrest six months later. American Journal of Public Health, 74 (5) 508-510.

Berkman, L. F. \& syme, S. L. (1979). Social networks, host resistance, and mortality: A nine-year follow-up study of Alameda County residents. American Journal of Epidemiology, 74 (2), 186-204.

Bloom, J. R. (1982). Support, accommodation to stress and adjustment to breast cancer. Soc. Sci. Med., 16, $1329-1338$.

Blumer, H. (1969). Symbolic interactionism; perspective and method. New Jersey: Prentice-Hall. Cassileth, B. R., Luske, E. J., Strouse, T. B., Miller, 
D. S., Brown, L. L., \& Cross, P. A. (1985). A psychological analysis of cancer patients and their nextof-kin. Cancer, $\underline{55}$ (1), 72-76.

Cobb, s. (1976). Social support as a moderator of life stress. Psychosomatic Medicine, 38 (5), 300-314.

Conn, J., Bobbitt, R., \& Bergner, M. (1978). Administration procedures and interviewer training for the sickness impact profile. University of Washington: Department of Health Services.

Deyo, R. A., Inui, T. S., Leininger, J., \& Overman, H. (1984). Physical and psychosocial function in rheumatoid arthritis: clinical use of a self-administered health status instrument. Arch Intern Med, 142, 879-882.

Dirksen, S. R. (1989). Perceived well-being in malignant melanoma survivors. Oncology Nursing Forum, 16 (3), $353-358$.

Driever, M. J. \& McCorkle, R. (1984). Patient concerns at 3 and 6 months postdiagnosis. Cancer Nursing 235-241.

Frank-stromborg, M. (2988). Instruments for clinical nursing research. Connecticut: Appleton \& Lange. Gilson, B. S., Gilson, J. S., Bergner, M., Bobbitt, R. A., Kressel, S., Pollard, W. E., \& Vesselago, M. (1975). The sickness impact profile. American Journal Public Health, $\underline{65}(12), 1304-1310$.

Given, B. A. \& Given, C. W. (1984). Creating a climate for compliance. Cancer Nursing, 139-147. 
Groenwald, S. L. (1987). Cancer nursing principles and practice. Boston: Jones \& Bartlett.

Heaton, R. K., Grant, I., MeSweeny, A. J., Adams, K. M., \& Petty, T. L. (1983). Psychologic effects of continuous and nocturnal oxygen therapy in hypoxemic chronic obstructive pulmonary disease. Arch Intern. Med, 143, 1941-1947.

Holland, J. C. \& Mastrovitt, R. (1980). Psychologic adaptation to breast cancer. Cancer, 46, 1045-1052.

Kesselring, A., Dodd, M. J., Lindsey, A. M., \& Strauss, A. I. (1986). Attitudes of patients living in Switzerland about cancer and treatment. Cancer Nursing, $\underline{9}$ (2), 77-85.

Kesselring, A., Lindsey, A. M., Dodd, M. J., \& Lovejoy, N. C. (1986). Social network and support perceived by Swiss cancer patients, $9(4), 156-163$.

Levy, R. (1983). Social support and compliance: A selective review and critique of treatment integrity and outcome measurement. Social science Medicine, 17 (18), $1329-1338$.

Liang, M. H., Cullen, K., \& Larson, M. (1982). In search of a more perfect mousetrap (health status or quality of life instrument). $\underline{J}$ Rheumatol, $\underline{9}$ (5), 775-780. Lin, N., Ensel, W. M., Simeone, R. S., \& Kuo, W. (1979). Social support, stressful life events, and illness: A model and empirical test. Journal of Health and Social 
Behavior, 28, 108-119.

Lindsey, A. M., Ahmed, N., \& Dodd, M. J. (1985). Social

support: Network and quality as perceived by

Egyptian cancer patients. Cancer Nursing, $\underline{8}$ (I), 37-42.

Lindsey, A. M., Dodd, M. J., \& Chen, S. (1985), Social

support network of Taiwanese cancer patients. Int. J.

Nurs. Stud., 22 (2), 149-164.

Lindsey, A. M., Norbeck, J. S., Carrieri, V. L., \& Perry, E. (1981). Social support and health outcomes in post

mastectomy women: A review. Cancer Nursing, 377-384.

Lorig, K., Chastain, R. L., Ung, E., Shoor, S., \& Holman, H. (1989). Development and evaluation of a scale to measure perceived self-efficacy in people with arthritis.

Arthritis and Rheumatism, 32 (1), 37-44.

Lubkin, I. M. (1986). Chronic illness impact and interventions. Boston: Jones \& Bartlett.

MacVicar, M. G. \& Archbold, P. (1976). A framework for family assessment in chronic illness. Oncology Nursing Forum, 15 (2), 181-194.

Manchester-Berger, J. (1985). Crisis intervention: A dropin support group for cancer patients and their families. Social Work in Health Care, 10 (2), 81-93.

Maxwell, M. B. (1982). The use of social networks to help cancer patients maximize support. Cancer Nursing, 275-281.

McLean, A., Dikman, S., \& Temkin, N. (1984). Psychosocial 
functioning at one month after head injury.

Neurosurgery, 14 (4), 393-397.

McGough, K. N. (1990). Assessing social support of people with aids. Oncology Nursing Forum. 17 (1), 31-35.

McSweeny, A. J., Grant, I., Heaton, R. K., Adams, K. M. \&

Timms, R. M. (1982). Archives of Internal Medicine, 142, $473-478$.

Mishel, M. H., Hostetter, T., King, B., \& Graham, V. (1984). Predictors of psychosocial adjustment in patients newly diagnosed with gynecological cancer. Cancer Nursing, $291-300$.

Musci, E. C. \& Dodd, M. J. (1990). Predicting self-care with patients and family members' affective states and family functioning. Oncology Nursing Forum, 17 (3), $394-400$.

O'Connor, A. P. Wicker, C. A., \& Germino, B. B. (1990). Understanding the cancer patient's search for meaning. Cancer Nursing, 13 (3), 167-175.

Ott, C. R., Sivarajan, E. S., Newton, K. M., Almes, M. J., Bruce, R. A., Bergner, M. \& Gilson, B. S. (1983). A controlled randomized study of early cardiac rehabilitation: The sickness impact profile as an assessment tool. Heart and Lung, 12 (2), 162-170. Pollard, W. E., Bobbitt, R. A., Bergner, M., Martin, D. P., \& Gilson, B. S. (1976). The sickness impact profile: Reliability of a health status measure. Medical Care, 14 
(2), 146-155.

stoner, C. (1985). Learned helplessness: Analysis and application. Oncology Nursing Forum, 12 (1), 31-35.

Sugerbaker, P. H., Barofsky, I., Rosenberg, S. A., \&

Granola, P. A. (1982). Quality of life assessment of patients in extremity sarcoma clinical trials. Surgery, 91 (1), 17-23.

Thorne, S. (1985). The family cancer experience. Cancer Nursing, $\underline{8}$ (5), 285-291.

Tringali C. A. (1986). The needs of family members of cancer patients. Oncology Nursing Forum, 13 (4), 65-70.

University of California, San Francisco, Department of Family Health Care Nursing (1981). Definition of family. Mission statement (Fall).

Webster's Ninth New Collegiate Dictionary. (1983). Springfield, MA: Merriam-Webster.

Welch-McCaffrey, D. (1985). Cancer, anxiety, and quality of 1ife. Cancer Nursing, 8 (3), 151-158.

Wortman, C. B. (1984). Social support and the cancer patient conceptual and methodologic issues. Cancer, $\underline{53}$ (10), 2339-2360. 
APPENDIX A

Sickness Impact Profile 

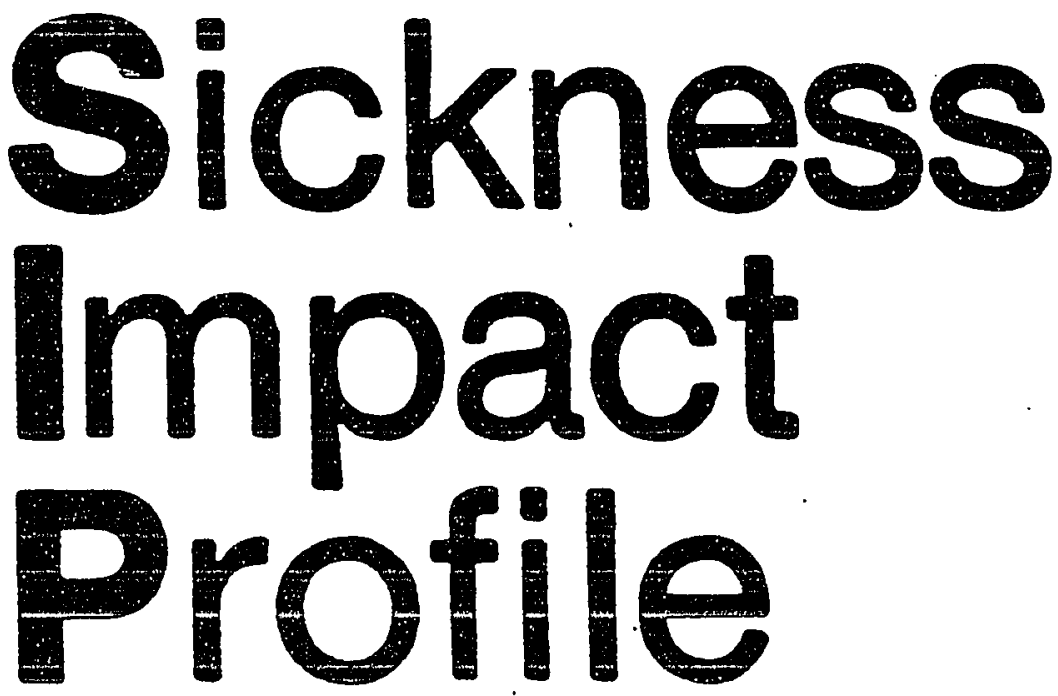

Copyright 1977

MRILY BEREUER 
please respond to (CheCX) only those statements that you are sure

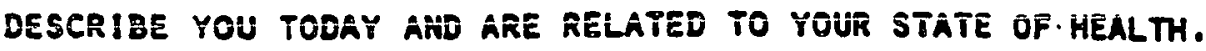

1. I spend much of the day lying dow in order to rest $(6>0-003)$

2. I sit during much of the day $(062-069)$

3. I am sleeping or dozing most of the time - day and night $(063-104)$

4. I lie down more often during the day in order to rest $(066-058)$

5. I sit around half-asleep $(065-006)$

6. I sleep less at nighe, for example, wake up too early. don't fall asleep for a long time. awaken frequently $(069.061)$

7. I sleep or nap nore during the day $(0,1-060)$ 
(EB-0>03)

PLEASE RESPOND TO (CHECK) OHLY THOSE STATEHERTS THAT YOU ARE SURE

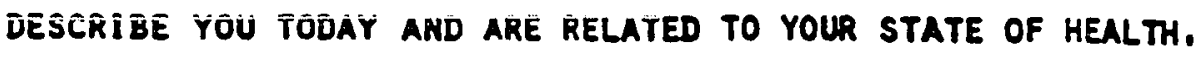
.

1. I say how bad or useless I an, for example, that I an - burden on others $(274-007)$

2. I laugh or cry suddenly $(272-061)$

3. I often moan and groan in pain or discomfort $(269-069)$

4. I have attempted suicide $(201-132)$

5. I act nervous or restless $(284-6+6)$

6. I keep rubbing or holding areas of my body that hurt or are uncomfortable $(262-062)$

7. I act irritable and imotient with myself. for exarole, talk badly about myself, swear at myself, blane myself for things that happen $(273-078)$

8. I qalk about the future in a hopeless may (283-009)

9. I get sudden frights $(278-074)$

CHECK HERE MHEN YOU MAVE READ ALL STATEMENTS ON THIS PAGE 
(BCM-2003)

PLEASE RESPOND to (CHECK) QNLY THOSE STATEMENTS THAT YOU ARE SURE DESCRIBE YOU TODAY AND ARE RELATED TO YOUR STATE OF HEALTH.

1. I maki difficult moves with help, for example, getting into or out of cars, bathtubs $(168.004)$

2. I do not move into or out of bed or chair by melf but an noved by 1 person or mechanical aid

$(170-121)$

3. I stand only for short periods of time

(155-072)

4. I do not maintain balance

$(166-090)$

5. I move my hands or fingers with some limitation or difficulty

$(1320.064)$

6. I stand up only with soneone's help

$(165-100)$

7. I kneel, stoop, or bend down only by holding on to something

8. I am in a restricted position all the time

$(271-066)$

9. I ar: very clumsy in body moverents

10. I get in and out of bed or chairs by grasping something for support or using a cane or walker

11. ! stay lying down most of the time

12. I change position frequently

13. I hold on to something to move myself around in bed

14. I do not bathe ayself completely, for example, require assistance with bathing

15. I do not bathe myself at all, but as bathed by someone else

16. I use bedpan wtth assistance $(292-116)$

17. I have trouble getting shoes, socks, or stockings on

$(305-057)$

18. I do not have control of my bladder $(290-126)$ 


\section{(CONTIMUED FROM PAGE 7)}

19. I do not fasten ro clothing, for example, require assistance fith buttons, zippers. shoelaces

$(298-074)$

20. 1 spend most of the time partly undressed or in pajanas

21. I do not have control of wo bavels $(302-074)$

22. I dress ayself, bue do so very slasly $(295-128)$.

23. I get dressed only with someone's help $(300-043)$ (297-0.8)

Check here when you have read all statements on this page

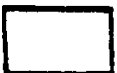


(hM-OCos)

THIS GROUP OF STATEMENTS HAS TO DO WITH ANY WORK YOU USUALLY DO IN CARING FOR YOUR HOME OR YARD. CONSIDER-

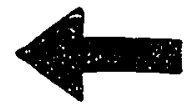
ING JUST THOSE THINGS THAT YOU DO, PLEASE RESPOND TO (CHECK) OALY THOSE STATEMENTS THAT YOU ARE SURE DESCRIBE YOU TODAY AND ARE RELATED TO YOUR STATE OF MEALTH

1. I do work around the house only for short perlods of tine or rest often $(117-056)$

2. I an doing less of the regular datly work around the house than would usually do $(129-0.4)$

3. I am not doing any of the regular dafly work around the house that I would usually do

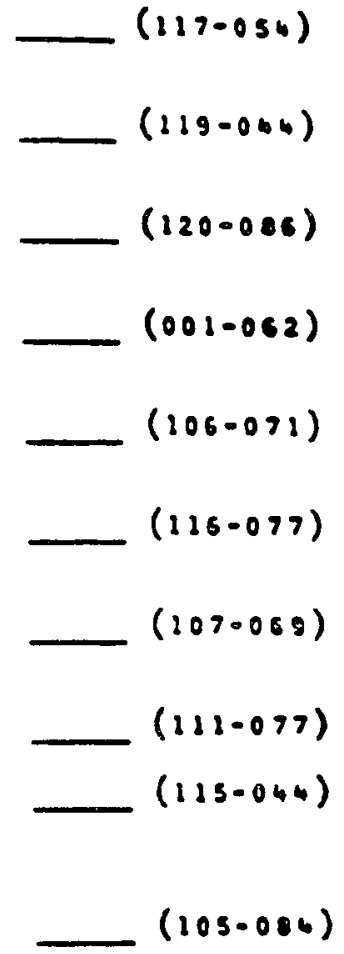

CHECK HERE WHEN YOU haVE READ ALL STATEMENTS ON THIS PAGE 
$(M-0,13)$

PLEASE RESPOND TO (CHECK) OHLY THOSE STATEMENTS THAT YOU ARE SURE DESCRIBE YOU TODAY AND ARE RELATED TO YOUR STATE OF HEALTH,

1. I an getting around only within one butlding $(134008)$

2. I stay within one room $(128-106)$

3. I am staying in bed more $(130-0.1)$

4. I an staying in bed most of the time $(131-109)$

5. I am not now using public transportation $(140-041)$

6. I stay home most of the time

$(233-066)$

7. I an only going to places with restroous nearby $(125-056)$

8. I an not going into tow $(124-060)$

9. I stay away from home only for brief periods of tice $(139-054)$

10. I do not get around in the dart or in unlit places without someone's help $(121-072)$ CHECK HERE WHEN YOU haVe READ ALL STATEMENTS ON thIS PAge 
$(s 1-1450)$

PLEASE RESPOND TO (CHECK) OMLY THOSE STATEMENTS THAT YOU ARE SURE DESCRIBE YOU TODAY AND ARE RELATED TO YOUR STATE OF HEALTH.

1. I an going oue less to visit people

2. I am not going out to viste people at all

$(028-064)$

3. I show less interest in other people's problees, for example, don't ilsten when they tell me about their probleas, don't offer to help

$(029-101)$

4. I often act irritable toward those around 2 , for example, snap at people, give sharp answers. criticize eastly

5. I show less affection

6. I am doing fewer social activities with groups of people

7. I an eutting down the length of visits with friends

8. I an avoiding social visies from others

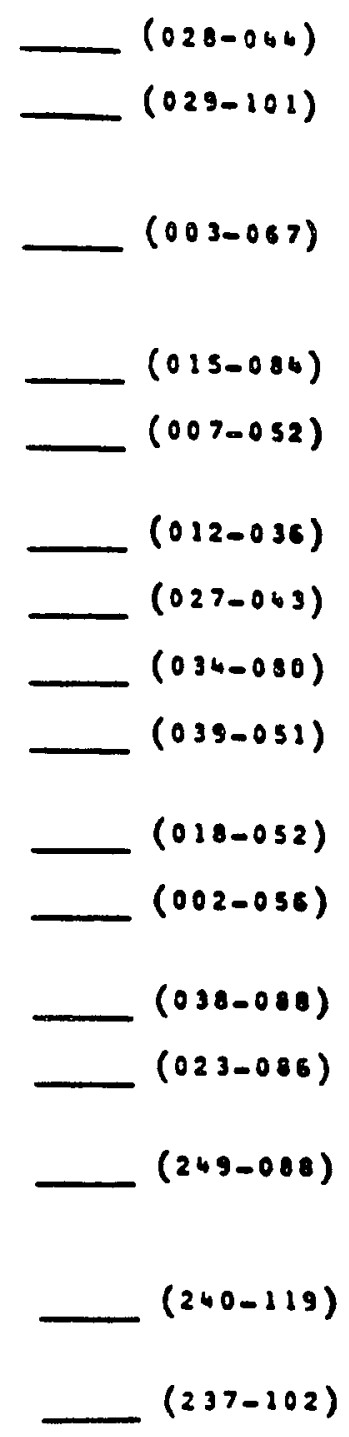

9. My sexual activity is decreased

10. I often express concern over what might be happening to un health

11. I taik less with those around we

12. I make many demands, for example, insist that people do things for me, tell them how to do things

$(038-088)$

13. I stay alone much of the tine

14. I act disagreeable to family menbers, for example, I aet spitefur. I an stubborn

15. I have frequent outbursts of anger at fant ly meabers, for example, strike at them, scream, throw things at then

16. I isolate myself as much as 1 can from the rest of the fanily 


\section{(CONTINUED FROM PAGE 11 )}

17. I am paying less attention to the childran

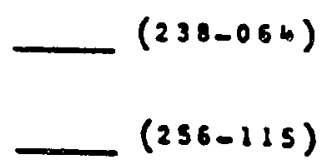
away froe then

19. I am not doing the things I usually do to take care of ov children or fanily $(242-099)$

20. I an not joking with fanily members as I usually do $(255-043)$

CHECK HERE WHEN YOU haVe READ ALL STATEMENTS ON THIS PAgE 
$(A-0842)$

PLEASE RESPOND TO (CHECK) ONLY THOSE STATEMENTS THAT YOU ARE SURE DESCRIBE YOU TODAY AND ARE RELATED TO YOUR STATE OF HEALTH.

1. I walk shorter distances or stop to rest often

2. I do not walk up or down hills

3. I use stairs only with mechanical support, for exanple. handrail, cane, crutches $(042-067)$

4. I walk up or down stairs only with assistance from someone else

$$
\begin{aligned}
& (050-040) \\
& -(046-056)
\end{aligned}
$$

I get around in a wheelchair

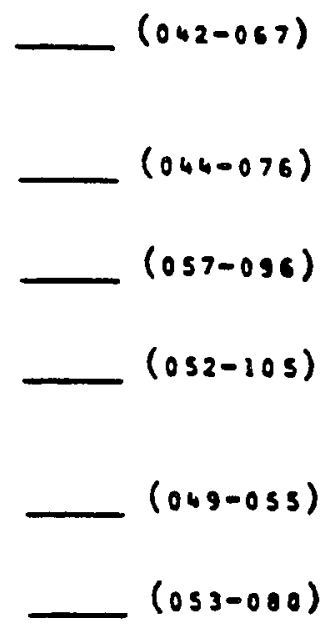

8. I walk only with help from someone

9. I go up and down stairs dore slowly, for example, one step at a time, stop often

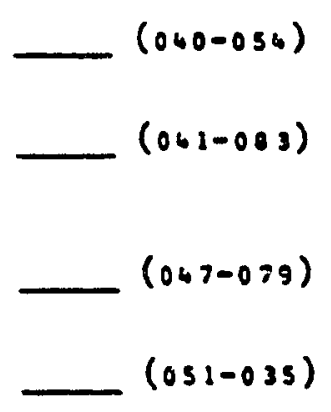

12. I walk nore slowily

IS PAGE

CHECK HERE WHEN YOU HAVE READ ALL STATEMENTS ON THIS PAGE 
$(A B-0777)$

PLEASE RESPOND TO (CHECK) QNLY THOSE STATEMENTS THAT YOU ARE SURE DESCRIBE YOU TODAY AND ARE RELATED TO YOUR STATE OF HEALTH.

1. I an confused and start several actions at a time $(223-090)$

2. I have more minor accidents, for example, drop things. trip and fall, bump into things $(236-075)$

3. I react slowly to things that are sald or done $(228-059)$

4. I do not finish things I start $(227-067)$

5. I have difficulty reasoning and solving problens, for example. making plans, making decistons, leaming new things

6. I sometimes behave as if I were confused or disortented in place or tiane, for example, where $I \mathrm{am}$, who is around, directions, what day it is $(231-113)$

7. I forget a lot, for exanple. things that happened recently, where I put things. appointments

8. I do not keep at attention on any activity for long $(220-067)$

9. I make more aistakes than usual $(225-064)$

10. I have difficulty doing activities involving concentration and thinking $(217-000)$

CHECK here hHEN you have read aLL statements ON thIS PAge 
$(c-0,25)$

PLEASE RESPOND TO (CHECK) ONLY THOSE STATEMENTS THAT YOU ARE SURE DESCRIBE YOU TODAY AND ARE RELATED TO YOUR STATE OF HEALTH.

1. i an having trouble writing or typing $(191-0>0)$

2. I cormunicate mostly by gestures, for example, moving head, polnting, sign language $(177-102)$

3. My speech is understood only by a few people who know me well $(179-093)$

4. I often lose control of ay volce when 1 talk, for example, no voice gets louder or softer. trembles, changes unexpectedly

5. ? don't write except to sign my name $(100-003)$

6. I carry on a conversation only when very close to the other person or looking at him $(178-069)$

7. I have difficulty speaking, for example, get stuck, stutter, stammer, slur ny words

8. I an understood with difficulty $(200-007)$

9. I to not speat clearly when I am under stress $(201-064)$

CHECK HERE WHEN YOU haVE READ ALL STATEMENTS ON tHIS PAge 
THE NEXT GROUP OF STATEMENTS HAS TO DO WITH ANY WORK YOU USUALLY DO OTHER THAN MANAGIHG YOUR HOME. BY THIS WE MEAK ANYTHING THAT YOU REGARD AS WORK THAT YOU DO ON A REGULAR BASIS.

DO YOU USUALLY DO WORK OTHER THAY MANAGIHG YOUR HOME?

IF yOU ANSHERED yeS, gO ON TO THE NEXT PAGE.

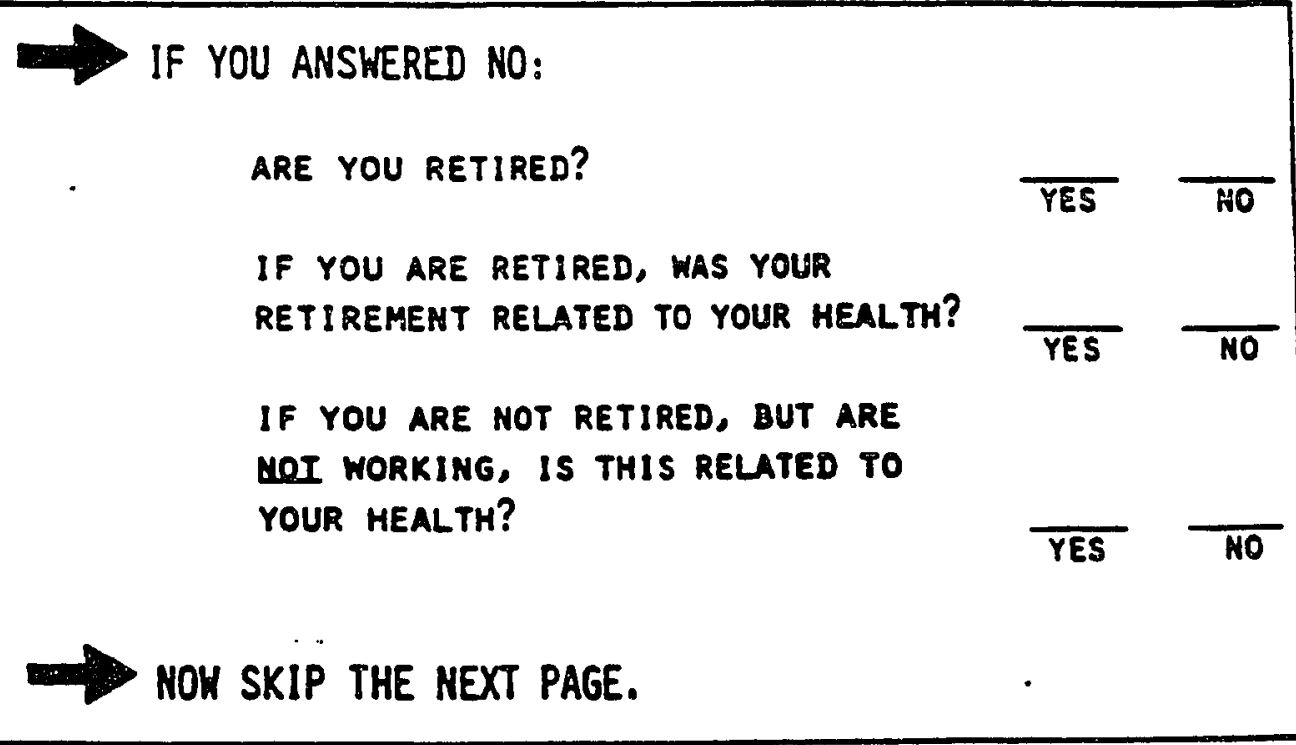


$(W-0525)$

\section{IF YOU ARE NOT WORKIHG AND IT IS MOT BECAUSE OF YOUR HEALTH, PLEASE SKIP THIS PAGE.}

NOW CONSIDER THE WORK YOU DO AND RESPOND TO (CHECK) ONLY THOSE STATEMENTS THAT YOU ARE SURE DESCRIBE YOU TODAY AND ARE RELATED TO YOUR STATE OF HEALTH. (IF TODAY IS A SATURDAY OR SUNDAY OR SOME OTHER DAY THAT YOU WOULD USUALLY HAVE OFF, PLEASE RESPOND AS IF TODAY WERE A WORKIIIG DAY.)

1. I an not working at all $(100-361)$

(IF YOU OECKED THIS STATEMENT, SKIP TO THE NEXT PNEE.)

2. i an doing part of my job at home $(084-017)$

3. I am not accomplishing as much as usual at work $(096-055)$

4. Dften act frritable toward my work assoctates. for example, snap at them, give sharp answers. reriticize easily

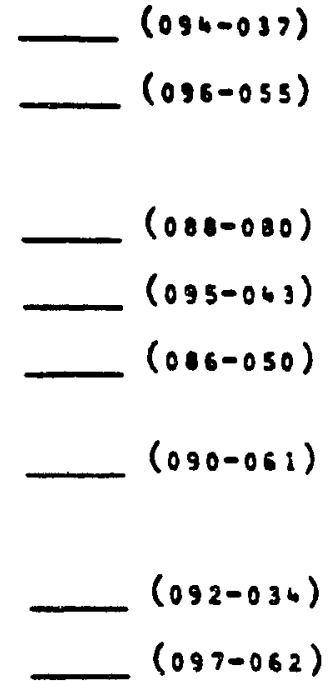

9. I do not do mo job as carefully and accuracely as usual $(097-062)$

CHECK hERE WHEN YOU haVE READ ALL STATEMENTS OH THIS PAGE 
$(E-0705)$

PLEASE RESPOND TO (CHECK) ONLY THOSE STATEMENTS THAT YOU ARE SURE DESCRIBE YOU TODAY AND ARE RELATED TO YOUR STATE OF HEALTH.

1. I an eating much less than usual $(0.5-037)$

2. I feed myself but only by using specially prepared food or utensils $(073-077)$

3. I am eating special or different food, for example, soft food, bland diet, low-salt, lorisfat, low-sugar $(081-0.63)$

4. I eat no food at all but am taking fluids $(077-106)$

5. i just pick or nibble at my food $(003-039)$

6. I an drinking less fluids $(000-036)$

7. I' feed nyself with help fram sareone else $(076-099)$

8. I do not feed nisself at all, but must be fed $(075-117)$

9. I an eating no food at all, nutrition is taken through tubes or intravenous flutds

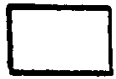


THIS GROUP OF STATEMENTS HAS TO DO WITH ACTIVITIES YOU USUALLY DO IN YOUR FREE TIME. THESE ACTIVITIES

ARE THINGS THAT YOU MIGHT DO FOR RELAXATION, TO PASS

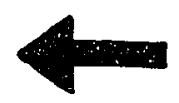

THE TIME, OR FOR ENTERTAINMENT. PLEASE RESPOND TO

(CHECK) ONLY THOSE STATEMENTS THAT YOU ARE SURE

DESCRIBE YOU TODAY AND ARE RELATED TO YOUR STATE OF

HEALTH. 1. I do my hobbles and recreation for shorter periods
of time $(215-039)$

2. I am going out for entertainment less often

3. I am cutting down on some of niy usual inactive recreation and pastimes, for example, watching TV, playing cards, reading

$(207-059)$

4. I am not doing any of my usual inactive recreation and pastimes, for example, watching TV, playing cards, reading $(208-084)$

5. I am doing more inactive pastimes in place of my other usual activities

$(211-051)$

6. I an doing fewer commuity activities

$(216-033)$

7. I an cuteing down on soane of any usual physical recreation or activities

8. I an not doing any of my usual physical recreation or activities

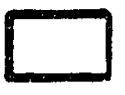


APPENDIX B

Consent From Institutional Review Board 


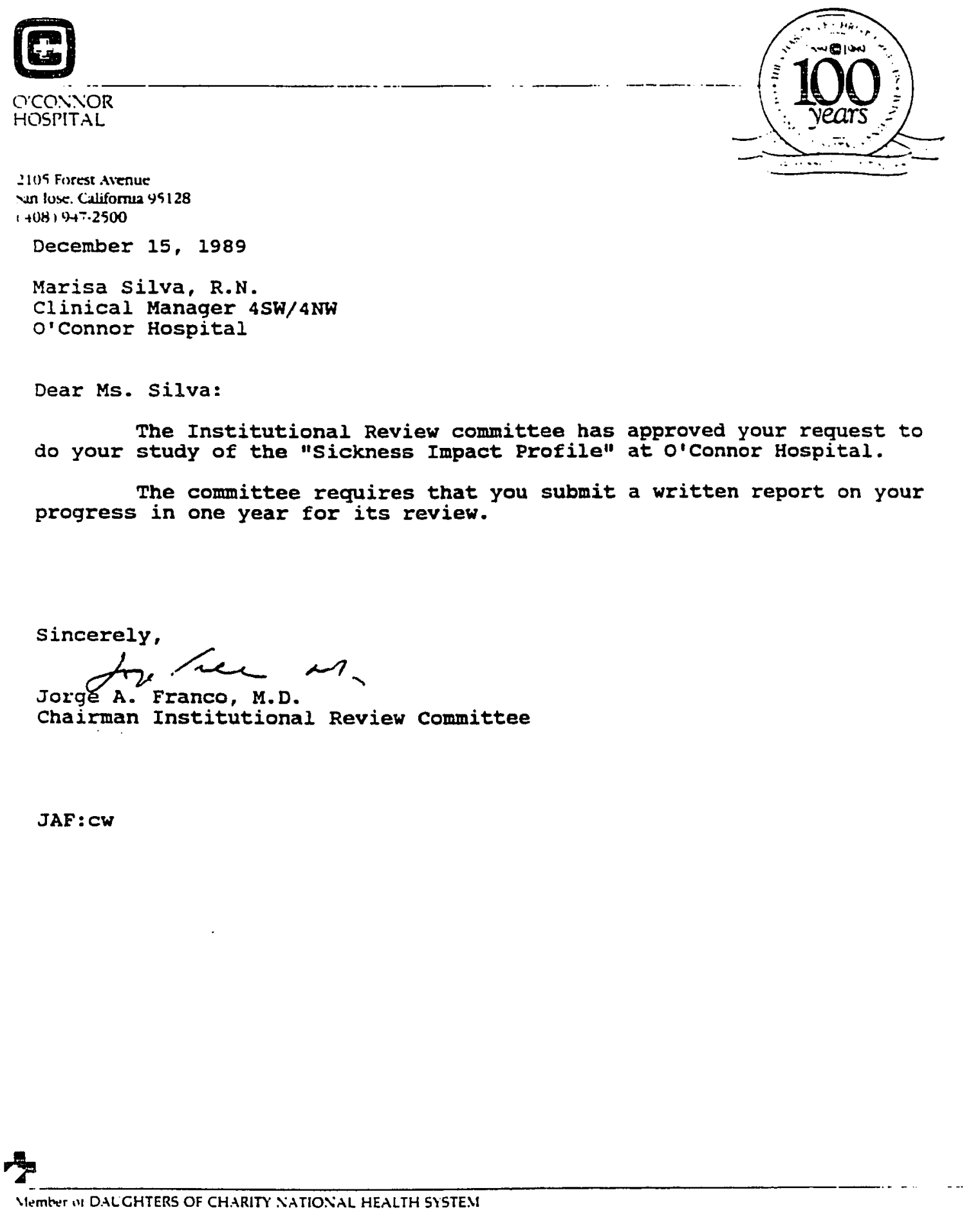


APPENDIX C

Informed Consent of Subject 


\section{AGREEMENT TO PARTICIPATE IN RESEARCH AT SAN JOSE STATE UN IVERS ITY}

RESPONSIBLE INVESTIGATOR: MARISA A. SILVA RN, BSN, PHN TITLE OF PROTOCOL: THE SICKNESS IMPACT PROFILE

I have been asked to participate in a research study that is investigating how the cancer patient's ability to maintain self-care activities is altered due to the impact of cancer. The results of this study should further our understanding of how cancer affects the cancer patient's ability to carry out normal daily activities. We also should learn more about how cancer is perceived by the patient and his/her primary caregiver in relation to carrying out these normal daily activities.

I understand that:

1) I will be asked to fill out a questionnaire in the hospital which will take approximately thirty (30) minutes to complete. I will not be allowed to discuss the questionnaire with anyone except Marisa Silva until I have completed all of the questions. Marisa Silva will clarify any questions I have while I am completing the questionnaire. I understand that the questionnaire is answered by checking the statements that describe the cancer patient at that particular moment.

2) The possible risks of this study are that I may become fatigued completing a questionnaire that takes approximately 30 minutes and that I may experience some psychological stress due to the personal nature of the questions. I understand that, if I become too tired, the questionnaire will be stopped.

3) The potential benefits are that I may learn something new about myself by answering the questions honestiy and the questionnaire may be a valuable assessment of personal needs in the hospital and/or home. The interaction may also be personally supportive. 
4) The results from this study may be published, but any information from this study that can be identified with me will remain confidential and will be disclosed only with my permission. I understand that names will not be associated with the questionnaires so as to keep the results confidential. I also understand that whether or not I participate will not prejudice me or my medical care.

5) I will not receive compensation for completing the questionnaire.

6) Any questions about my participation in this study will be answered by Marisa Silva (Phone: (W) 408-947-2804;

(H) 408-265-5425). If I am not satisfied with the manner in which this study is being conducted, I may report (anonymously if $I$ wish) any complaints to the Institutional Review committee of Hospital by calling

or by addressing a letter to the Institutional Review committee of at

For questions or complaints about research subject's rights I may contact serena stanford, PhD. (Associate Academic Vice President for Graduate Studies, San Jose state University) at 408-924-2480.

7) My consent is being given voluntarily without being coerced. I may refuse to participate in this study or in any part of this study, and I may withdraw at any time, without prejudice to my relations with san Jose State University or

8) I have received a copy of this consent form for my file.

I HAVE MADE A DECISION WHETHER OR NOT TO PARTICIPATE. MY SIGNATURE INDICATES THAT I HAVE READ THE INFORMATION PROVIDED ABOVE AND THAT I HAVE DECIDED TO PARTICIPATE.

DATE

Subject's Signature 
APPENDIX D

Cancer Patient Biographical Data Form 


\section{CANCER PATIENT: BIOGRAPHICAL DATA}

Age:

Sex:

Ethnic origin:

Occupation:

Highest level of education/degree:

Marital status:

Relationship to primary caregiver:

Type of cancer:

How long since diagnosis (check one)

Less than 6 months

6 months to I year

1 year to 5 years

5 years or longer 
APPENDIX E

Primary Caregiver Biographical Data Form 


\section{PRIMARY CAREGIVER: BIOGRAPHICAL DATA}

Age:

Sex:

Ethnic origin:

Occupation:

Highest level of education/degree:

Marital status:

Relationship to cancer patient:

Type of cancer patient has:

How long since patient's diagnosis (check one)

Less than 6 months

6 months to 1 year

1 year to 5 years

5 years or longer 
APPENDIX F

Cover Letter to Dr. Bergner 
911 Syida Drive

Pacific Grove, Ca 93950

November 28,1988

Dr. Marilyn Bergner

John Hopkins University

School of Hygiene and Public Health

624 North Broadway

Baltimore, MD 21205

Dear Dr. Bergner:

Thank you for discussing the Sickness Impact Profile (S.I.P.) with me today. I have done a great deal of research and have read several studies which utilize this instrument.

I am a Master in Nursing candidate at San Jose state University in California. I am presently working on my thesis and respectfully request permission to utilize the S.I.P. for my research.

In my studies I have found the S.I.P. described as: A behaviorally based measure of the impact of sickness, a questionnaire which inquires about a variety of daily functions, an instrument which describes behavioral dysfunction in daily activities, a "broad-based" assessment of life quality, and a behavioral measure independent of diagnostic criteria which relies solely on an individual's perception of the impact of sickness on his usual activities of daily living.

The population which I am studying is cancer clients. I propose to utilize the S.I.P. on cancer clients as a behavioral measure of ability to maintain functional status despite a chronic illness diagnosis. I realize that the S.I.P. measures dysfunction--the lower the S.I.P. score the higher I will rate functional status. I also wish to administer the S.I.P. to the cancer client's primary caregiver as determined by the cancer client. I will ask the primary caregiver to answer the S.I.P. as he/she perceives the cancer client would answer the questions. I will compare the results to determine how closely both subject groups perceive the impact of the sickness. Neither subject will have access to the other's answers, as I administer the tool.

My readers at the University have approved the use of your 
tool on the contingency that I receive written permission from you. I would very much appreciate a brief letter of permission from you to utilize the S.I.P. accompanying the packet.

If you have any questions, you may call me at (408) 3732566 , or write to me at the above address. Thank you for your attention.

Very truly yours,

MARISA A. SILVA, R.N., B.S.N. 
APPENDIX G

Consent for Use of the

Sickness Impact Profile 


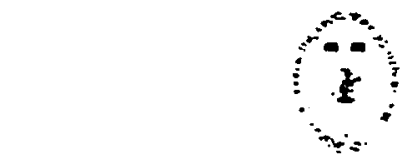

THE JOHNS HOPKINS UNIVERSITY

school of Hygiene and Public Health

Hearn Services Research and

Marisa A. Silva, R.N., B.S.N., P.H.N.

911 Syida Drive

Pacific Grove, CA. 93950

Dear Ms. Silva:

This letter grants you permission to use the Sickness Impact Profile in your research. In return, I would appreciate receiving a detailed description of the research you will be doing and a final report of the results when it is completed.

MB:dep

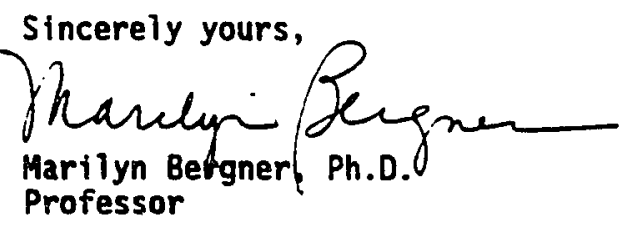


APPENDIX H

SIP Dimension and Total Scores 
SIP Dimension and Total Scores

\begin{tabular}{|c|c|c|c|c|}
\hline $\begin{array}{l}\text { Subject } \\
\text { Number }\end{array}$ & $\begin{array}{l}\text { Physical } \\
\text { Dimension }\end{array}$ & $\begin{array}{l}\text { Psychosocial } \\
\text { Dimension }\end{array}$ & $\begin{array}{l}\text { "Personal } \\
\text { Habits" }\end{array}$ & $\begin{array}{l}\text { TOTAL } \\
\text { SCORE }\end{array}$ \\
\hline $\begin{array}{l}1 A \\
1 B \\
2 A \\
2 B \\
3 A \\
3 B \\
4 A \\
4 B \\
5 A \\
5 B \\
6 A \\
6 B \\
7 A \\
7 B \\
8 A \\
8 B \\
9 A \\
9 B \\
10 A \\
10 B \\
11 A \\
11 B \\
12 A \\
12 B \\
13 A \\
13 B \\
14 A \\
14 B \\
15 A \\
15 B \\
16 A \\
16 B \\
17 A \\
17 B \\
18 A \\
18 B\end{array}$ & $\begin{array}{r}33.0 \\
107.2 \\
99.3 \\
86.1 \\
201.8 \\
201.2 \\
68.5 \\
71.7 \\
59.3 \\
91.7 \\
151.5 \\
121.3 \\
0.0 \\
40.3 \\
84.1 \\
84.1 \\
77.2 \\
27.8 \\
134.1 \\
108.1 \\
0.0 \\
28.9 \\
0.0 \\
9.2 \\
0.0 \\
0.0 \\
34.9 \\
80.8 \\
113.4 \\
215.8 \\
132.4 \\
110.9 \\
34.1 \\
30.8 \\
120.1 \\
166.7\end{array}$ & $\begin{array}{r}80.1 \\
149.3 \\
30.8 \\
86.6 \\
78.9 \\
98.6 \\
33.7 \\
60.6 \\
67.0 \\
115.4 \\
153.2 \\
85.8 \\
2.4 \\
5.5 \\
20.9 \\
111.3 \\
103.3 \\
82.5 \\
48.8 \\
19.6 \\
3.5 \\
3.5 \\
30.8 \\
43.6 \\
0.0 \\
25.9 \\
57.0 \\
83.4 \\
52.9 \\
146.7 \\
193.9 \\
218.2 \\
3.0 \\
32.0 \\
135.7 \\
240.7\end{array}$ & $\begin{array}{r}91.6 \\
114.2 \\
266.1 \\
191.6 \\
160.2 \\
236.1 \\
200.2 \\
182.1 \\
86.1 \\
144.9 \\
275.8 \\
225.7 \\
73.2 \\
86.6 \\
58.4 \\
12.7 \\
160.6 \\
58.4 \\
140.3 \\
98.1 \\
42.0 \\
28.1 \\
27.1 \\
64.0 \\
70.1 \\
6.6 \\
134.7 \\
280.7 \\
264.8 \\
216.3 \\
223.7 \\
242.6 \\
22.0 \\
57.7 \\
164.0 \\
168.0\end{array}$ & $\begin{array}{r}204.8 \\
370.6 \\
396.2 \\
364.3 \\
440.8 \\
535.9 \\
302.4 \\
313.4 \\
212.5 \\
352.0 \\
580.4 \\
432.8 \\
75.7 \\
132.4 \\
163.4 \\
108.0 \\
341.1 \\
168.7 \\
323.2 \\
225.7 \\
45.5 \\
60.5 \\
57.9 \\
116.8 \\
70.1 \\
32.4 \\
226.5 \\
444.9 \\
431.0 \\
578.8 \\
550.0 \\
571.8 \\
59.2 \\
120.7 \\
419.7 \\
575.4\end{array}$ \\
\hline
\end{tabular}


SIP Dimension and Total scores (continued)

\begin{tabular}{|c|c|c|c|c|}
\hline $\begin{array}{l}\text { Subject } \\
\text { Number }\end{array}$ & $\begin{array}{l}\text { Physical } \\
\text { Dimension }\end{array}$ & $\begin{array}{l}\text { Psychosocial } \\
\text { Dimension }\end{array}$ & $\begin{array}{l}\text { "Personal } \\
\text { Habits" }\end{array}$ & $\begin{array}{l}\text { TOTAL } \\
\text { SCORE }\end{array}$ \\
\hline $\begin{array}{l}19 A \\
19 B \\
20 A \\
20 B \\
21 A \\
21 B \\
22 A \\
22 B \\
23 A \\
23 B \\
24 A \\
24 B \\
25 A \\
25 B \\
26 A \\
26 B \\
27 A \\
27 B \\
28 A \\
28 B \\
29 A \\
29 B \\
30 A \\
30 B\end{array}$ & $\begin{array}{r}1.5 \\
0.0 \\
27.9 \\
25.8 \\
34.5 \\
0.0 \\
155.0 \\
201.9 \\
80.9 \\
105.3 \\
21.3 \\
1.5 \\
91.7 \\
98.8 \\
17.2 \\
33.7 \\
102.5 \\
86.9 \\
55.8 \\
55.8 \\
87.5 \\
107.9 \\
61.9 \\
56.1\end{array}$ & $\begin{array}{r}8.2 \\
16.6 \\
81.5 \\
36.0 \\
10.8 \\
15.1 \\
171.9 \\
249.3 \\
55.6 \\
72.5 \\
15.4 \\
12.4 \\
152.8 \\
167.4 \\
24.7 \\
26.3 \\
174.8 \\
115.8 \\
95.9 \\
86.3 \\
182.5 \\
213.0 \\
104.5 \\
141.8\end{array}$ & $\begin{array}{r}25.1 \\
35.9 \\
81.5 \\
65.1 \\
29.1 \\
33.0 \\
220.9 \\
281.5 \\
221.4 \\
271.7 \\
91.8 \\
75.4 \\
238.5 \\
258.9 \\
65.7 \\
45.7 \\
206.8 \\
176.3 \\
162.8 \\
176.5 \\
234.3 \\
243.3 \\
188.9 \\
185.4\end{array}$ & $\begin{array}{r}34.8 \\
48.6 \\
190.9 \\
126.9 \\
74.4 \\
48.1 \\
547.9 \\
732.7 \\
357.9 \\
449.5 \\
128.5 \\
89.2 \\
483.1 \\
525.1 \\
107.6 \\
105.7 \\
484.1 \\
379.0 \\
314.5 \\
318.6 \\
504.3 \\
564.1 \\
355.3 \\
383.4\end{array}$ \\
\hline
\end{tabular}

